\title{
A Comprehensive Bibliometric Analysis of the Energy Poverty Literature: From 1942 to 2020
}

\author{
Yuanhang ZHENG ${ }^{1}$, Zeshui XU ${ }^{2 *}$, Marinko SKARE ${ }^{3}$ and Matgorzata PORADA- \\ $\mathrm{ROCHON}^{4}$
}

\author{
Authors' affiliations and addresses: \\ ${ }^{1}$ Business School, Sichuan University, Chengdu \\ 610064, China \\ e-mail: yuanhang_zheng@foxmail.com \\ ${ }^{2}$ Business School, Sichuan University, Chengdu \\ 610064, China \\ e-mail: xuzeshui@263.net \\ ${ }^{3}$ Juraj Dobrila Univ Pula, Fac Econ \& Tourism \\ Dr Mijo Mirkovic, Preradoviceva 1-1, Pula \\ 52100, Croatia \\ e-mail: mskare@unipu.hr \\ ${ }^{4}$ University of Szczecin, Faculty of Economics, \\ Finance and Management, Szczecin, Poland \\ e-mail: malgorzata.rochon@wp.pl

\section{*Correspondence:} \\ Zeshui Xu, Business School, Sichuan University, \\ Chengdu 610064, China \\ e-mail: xuzeshui@263.net
}

Funding information:

The work was supported by the National Natural Science Foundation of China

No. 72071135,71771155

\section{Acknowledgement:}

The work was supported by the National Natural Science Foundation of China (No. 72071135, 71771155).

How to cite this article:

Zheng, Z., Xu, Z., Skare M. and Porada-Rochon, M. (2021). A Comprehensive Bibliometric Analysis of the Energy Poverty Literature: From 1942 to 2020. Acta Montanistica Slovaca, Volume 26 (3), 512-533

DOI:

https://doi.org/10.46544/AMS.v26i3.10

\begin{abstract}
Energy poverty is a serious social issue people worldwide are facing, having a negative impact on economic development, environmental governance, social stability, and people's lives. This paper aims to make a survey of energy poverty literature through bibliometric analysis. Searched by the subject as "energy poverty", "fuel poverty", "energy poor", "fuel poor", "energy shortage", "fuel shortage", 3,419 related documents are collected from the years 1942 to 2020 in journals indexed by Web of Science Core Collection. Firstly, fundamental characteristics of the published documents and journals display the annual trend and highly concerns based on recognised bibliometric indicators. With the support of a bibliometric review approach such as VOS viewer and CiteSpace software, the most productive countries/regions, the most influential institutions, and the most influential authors are identified. The cooperation profile of energy poverty researchers shows a predominance of international cooperation. Then, the theme is particularly analysed based on keywords from four aspects: keyword-burst detection, landscape view, timeline visualisation and major specialities. At last, we conclude the bibliometric overview with significant findings and future research in the field of energy poverty.
\end{abstract}

\section{Keywords}

Energy poverty; Bibliometric analysis; Citation and cooperation network; Major specialities analysis.

(C) 2021 by the authors. Submitted for possible open access publication under the terms and conditions of the Creative Commons Attribution (CC BY) license (http://creativecommons.org/licenses/by/4.0/). 


\section{Introduction}

Energy Poverty (EP), a global problem that has been intensified worldwide due to the financial crisis, has greatly aroused government and political party interest and has caused a major public impact on economic, environmental, and social development. Since its concept was first introduced by Isherwood and Hancock (Isherwood and Hancock, 1979) in 1979 due to the petroleum crisis (1973-1974) and its similar term named as fuel shortage was first appeared in 1942 (Hill, 1942), the research of EP has spread rapidly to a variety of countries, including European countries, Chile, China, New Zealand, etc. (Liddell, 2012; Urquiza et al., 2019; Tang and Liao, 2014; Howden-Chapman et al., 2012), with varying definitions of EP and measurements of how to assess this phenomenon.

In general, EP is defined as the phenomenon that the supply of energy cannot satisfy the household need of daily life and production (Nora et al., 2019). EP is assessed in different areas by different indicators, and a total of 71 indicators were systematically reviewed and compared based on some scientific principles and methods (Siksnelyte-Butkiene et al., 2021). In underdeveloped countries, indicators that assess access to energy are popular to measure $\mathrm{EP}$, while it is usual to assess the inequality produced by the costs of accessing such energy services in the developed countries. Simultaneously, there are multiple indicators like energy efficiency to evaluate the situation of EP in the developing countries (Urquiza et al., 2019; Nora et al., 2019). Making a general survey of EP research, most of them have paid attention to how EP directly slow down the development of the economy, society and environment, and lead to the decline of the quality of life and the deterioration of the physical and mental health of the family residents (González-Eguino, 2015). Lowans et al. (2021) investigated the state-of-theart research about not only energy (fuel) poverty but also transport poverty, with a view to evaluating how overlapping concepts may be unified in their measurement. Furthermore, it should not be neglected that the widespread EP worldwide is not an isolated phenomenon but instead should be dealt with in synergy with energy transition and climate change issues (Ürge-Vorsatz and Tirado Herrero, 2012; Von Stechow et al., 2015).

Bibliometric analysis traced back to the early $20^{\text {th }}$ century is an interdisciplinary science that uses mathematical and statistical methods to quantitatively analyse all knowledge (Tarragona et al., 2020; Wang et al., 2020; Yu et al., 2017, Wang et al., 2021). Its measurement objects mainly include a quantity of literature (the number and citation of journal papers), number of authors (individual collective or group), and number of vocabulary (all kinds of literature identifications). Thus, it is needed to explore the development of EP in general across history through bibliometric analysis. Some scholars have devoted themselves to this research field. On the one hand, Li et al. (2015) investigated the bibliometrics of EP in 2015 and made some contributions. Han and Wei (2021) studied a range of research of household consumption by bibliometrics and network analysis method, including energy conservation, EP, and energy efficiency. On the other hand, the status of $\mathrm{CO}_{2}$ conversion research in the past ten years was analysed through bibliometrics because addressing EP requires conversing $\mathrm{CO}_{2}$ into high added-value products (Xing et al., 2020). New clean energies were predicted by integrating bibliometric and patent analysis for improving the current situation of EP (Chen et al., 2010). However, in (Li et al., 2015), not only 269 publications were selected from 1981 to 2013, but also the survey contents need to be complemented. At the same time, EP is just one of parts of the main idea of (Han and Wei, 2021; Xing et al., 2020; Chen et al., 2010).

Therefore, to fill this gap, the paper is aimed to present a comprehensive and latest bibliometric review of EP literature. To be specific, three main purposes of this paper are as follows: (1) describe fundamental characteristics of documents related to EP, including the annual number of documents and annual total citations of documents, distribution of document types, research directions, dual-map overlay of journals on EP research, most productive journals and most cited documents. (2) elaborate where and who is concerned to EP, that is depicting the production number and citations of the country, institution, and author, and as well as the cooperation network among them. (3) analyse the main themes of EP according to clustering keywords. Clustering is a distinctive feature of CiteSpace, one of the bibliometric visualisation techniques, and the clustering results have been tested to be reliable (Chen, 2017; Chen, 2018). Based on the clustering results shown in CiteSpace, we analyse the theme and contents of each cluster according to keywords of citing articles and cited references.

The rest of the paper is constructed as follows: Section 2 introduces the methodology used in the bibliometric analysis. Then, Section 3 displays visualised results of EP research from three aspects, including some fundamental characteristics, the countries, institutions, and authors concerning the development of EP, and theme analysis through keywords. Finally, some conclusions and policy implications are exhibited in Section 4.

\section{Material and Methods}

To comprehensively review documents of EP from the perspective of history to its development, we collect reliable publications and utilise scientific bibliometric methods. Web of Sciences (WoS), owned by the company Thomson \& Reuters Corporation, is one of the widely accepted and frequently used databases for academic researchers around the world (Falagas et al., 2008) and provides detailed information for the quantification of scientific publications (Cortés-Sánchez, 2019). WoS has seven popular databases, including WoS Core Collection, 
Derwent Innovations Index, Inspec, KCI-Korean Journal Database, Medline, Russian Science Citation Index and SciELO Citation Index.

In this paper, scientific papers are collected from the WoS Core Collection database because the other databases have few publications on EP and are therefore discarded, without any interference with the general outcome of this study. WoS searches the title of the manuscript, its abstract, keywords, author, and Keywords Plus, when the field "Subject" is checked (De Paulo and Porto, 2017). For EP, the field "Subject" should be set as at least one of the following terms: "energy poverty*", "fuel poverty*", "energy poor*", "fuel poor*", "energy shortage*", "fuel shortage*". Some of the above search terms are recommended in (Urquiza et al., 2019; Li et al., 2015) and show a close relationship with the term "EP". The special character "*" is used at the end of some terms to identify restrictions, thereby getting more accurate results. The search is restricted to articles published between 1942 and 2020 since the first document was published in NATURE in 1942. Deriving data on Dec $4^{\text {th }}, 2020,3,419$ documents were retrieved after preliminary screening through title, abstract and keywords, which should be relevant to the topic of energy poverty. Then these documents were exported in plain text and Comma-Separated Values (CSV) file formats for the bibliometric analysis, including title, abstract, keywords, citations and references.

Based on the collected publications, the paper analyses the characteristics of EP publications from three aspects: (1) fundamental features, i.e., the productivity and influence of publications based on representative bibliometric indicators, such as the total number of publications (TP), the total number of citations (TC), the average citations per publications (AC); (2) the visual analysis results, that is, some visualisation networks presented in VOS viewer, such as citation network of authors, cooperation network of countries/regions, institutions and authors. (3) Major specialities analysis, that is the theme analysis through keywords, which is important in bibliometric analysis (Chen, 2017). Based on the clustering results shown in CiteSpace, we analyse the theme and contents of each cluster according to keywords of citing articles and cited references.

\section{Results and Discussion}

Based on the selected data and the useful techniques introduced in Section 2, some results can be obtained regarding the bibliometric analysis of EP, which are displayed from three aspects: fundamental characteristics of documents, the most productive/the closest cooperative countries, Institutions or authors, and themes analysis through keywords.

\section{Fundamental characteristics of documents related to EP}

Figures 1 (a) and (b) reveal annual TP and TC regarding EP, respectively. As is shown in Figure 1 (a), the first document existed in 1942, named "Effects of clothing and fuel shortage on health", and in 1956 appeared the second one. Then, a small number of scholars were interested in EP from 1969 to 2003. Since 2004, the subject of EP has become a hot research direction, and more and more scholars have paid attention to this field. Especially, the number of documents grew fast during the last fifteen years, beginning from 15 papers in 2004 to 515 papers in 2019 and 458 papers from Jan $1^{\text {st }}$ to Dec $2^{\text {nd }}$ in 2020. It is obvious that the number of published documents with respect to EP in the whole of 2020 and the next year will be no less than or more than the previous years from the rapid development trends.

Similarly, from Figure 1 (b), we can easily see that the first citation in the field of EP was in 1965. Then, between 1975 and 1991, annual TC fluctuated at a slightly low level. For example, 3 times in 1975, 12 times in 1983 and 3 times in 1991. Since 1992, annual TC increased rapidly, reaching 117 in 2001. It increased from 1,118 in 2011 to 11,999 in 2019 . Up to Dec $2^{\text {nd }}, 2020$, annual TC becomes 13,213 , and it will continuously rise up according to the increasing trend.

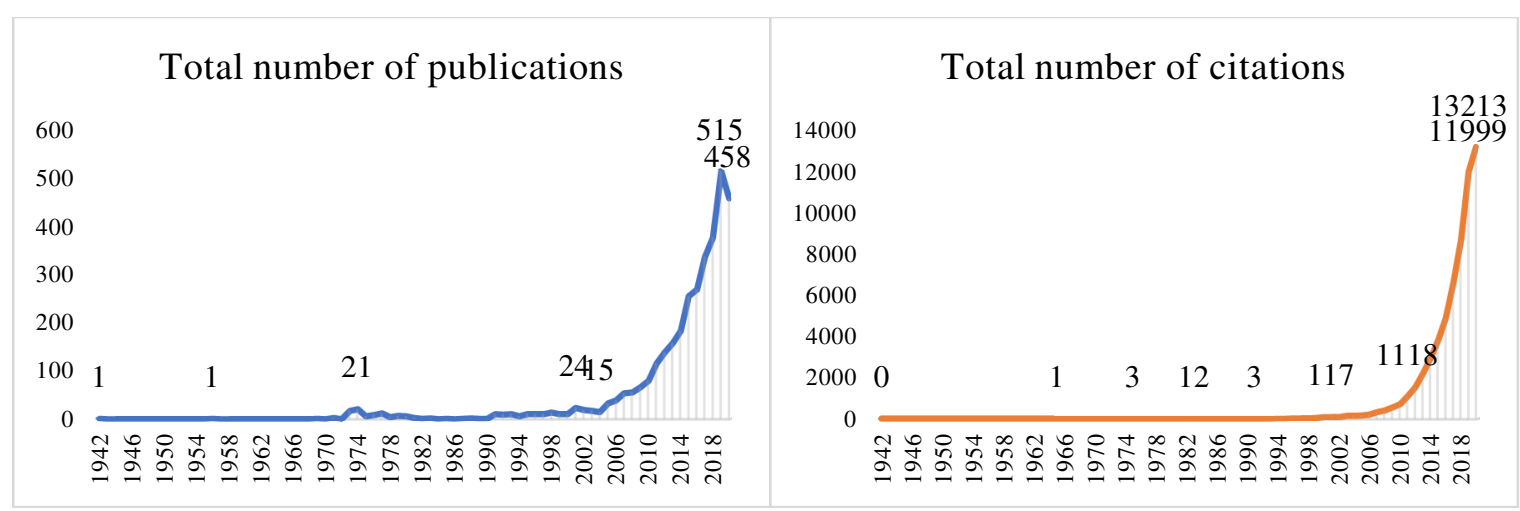

(a)

(b)

Fig. 1. (a) Annual total number of publications and (b) Annual total number of citations 
In WoS, all documents are divided into different types. It is noted that the sum of the number of documents of all types is greater than the number of selected documents because some documents only belong to a single type while others fall into two or more categories at the same time. The distribution of document types is displayed in Table 1.

Tab. 1. Distribution of document types

\begin{tabular}{|c|c|c|}
\hline Type & Number & Percentage \\
\hline ARTICLE & 2273 & $64.32 \%$ \\
\hline PROCEEDINGS PAPER & 754 & $21.34 \%$ \\
\hline REVIEW & 336 & $9.51 \%$ \\
\hline EDITORIAL MATERIAL & 63 & $1.78 \%$ \\
\hline EARLY ACCESS & 44 & $1.25 \%$ \\
\hline BOOK REVIEW & 18 & $0.51 \%$ \\
\hline NEWS ITEM & 13 & $0.37 \%$ \\
\hline LETTER & 9 & $0.25 \%$ \\
\hline NOTE & 8 & $0.23 \%$ \\
\hline MEETING ABSTRACT & 7 & $0.20 \%$ \\
\hline BOOK CHAPTER & 5 & $0.14 \%$ \\
\hline CORRECTION & 2 & $0.06 \%$ \\
\hline RETRACTED PUBLICATION & 1 & $0.03 \%$ \\
\hline REPRINT & 1 & $0.03 \%$ \\
\hline
\end{tabular}

14 types are collected in total, amongst which, the article occupies a comparatively great percentage (64.32\%) of all documents, with the number of 2,273 . Followed by is proceedings paper $(754,21.34 \%)$, review $(336,9.51 \%)$, editorial material $(63,1.78 \%)$, early access $(44,1.25 \%)$, book review $(18,0.51 \%)$, news item $(13,0.37 \%)$, letter $(9,0.25 \%)$, note $(8,0.23 \%)$, meeting abstract $(7,0.2 \%)$, book chapter $(5,0.14 \%)$, correction $(2,0.06 \%)$, retracted publication $(1,0.03 \%)$, and reprint $(1,0.03 \%)$, respectively. In sum, scholars mainly choose article and proceedings paper to publish their research results.

Every document has at least one of the research directions, so it is not surprising that the sum of the number of documents of all directions is far more than the total number of selected documents. Figure 2 shows Top 10 research directions of documents related to EP.

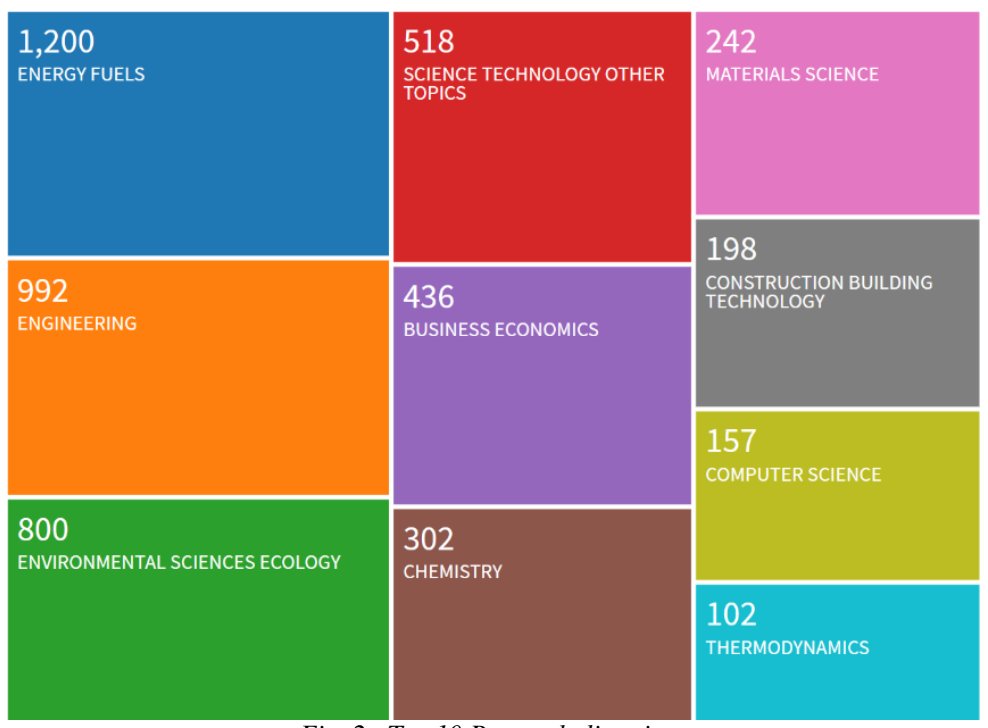

Fig. 2. Top 10 Research directions

From Figure 2, it is known that the most popular research directions in EP are energy fuels $(1,200)$ and engineering (992), which account for a high proportion of the total number. Environmental sciences ecology (800), science technology other topics (518), business economics (436) are three main research directions. Followed by is chemistry (302), materials science (242), construction building technology (198), computer science (157) and thermodynamics (102), respectively. According to the published documents, the research can be divided into two areas. On the one hand, many publications related to EP are concerned with the energy in society, so they are built from these directions, such as energy fuels, environmental sciences ecology and business economics; On the other hand, considerable published documents focus on energy in science and engineering. Thus, some research directions, such as engineering, science technology, other topics, chemistry, materials science, construction building technology and thermodynamics, are involved in publications related to EP.

Journal is one of the most important and the most used sources for publishing research results. The dual-map overlay of journals, proposed by Chen and Leydesdorff (2014), shows a macroscopic view of the distribution, the 
citation trajectory and the shift of gravity centre at the discipline level. As laid out in Figure 3, the dual-map consists of two maps of journals. On the left side is a map of source journals where an article on EP research is published, and on the right side is a map of target journals cited for published articles on the left (Chen, 2018). The citation links between them tell us what target journals the source journals cited from, and the largest circles in the left and right indicate disciplines with the most documents published (Aryadoust et al., 2019).

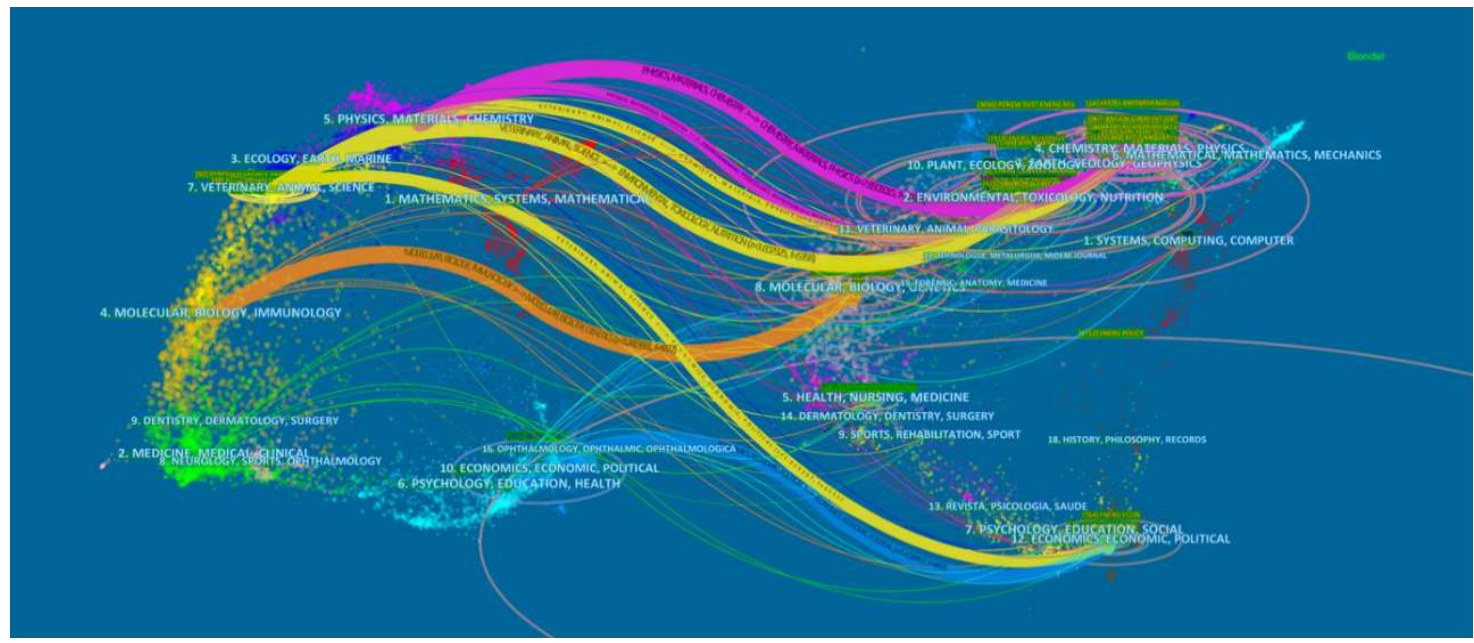

Fig. 3. Dual-map overlay of journals on EP research

To clearly represent the citation relationship between journals, citation links are bundled by using the Z-Sore function. As a result, seven main citation tracks are found from source journals to target journals, shown in Figure 3. They are from "Physics, Materials and Chemistry" to "Chemistry, Materials, and Physics" (Purple), from "Physics, Materials and Chemistry" to "Environmental, Toxicology, and Nutrition" (Purple), from "Veterinary, Animal and Science" to "Chemistry, Materials, and Physics" (Yellow), from "Veterinary, Animal and Science" to "Environmental, Toxicology, and Nutrition" (Yellow), from "Veterinary, Animal and Science" to "Economics, Economic and Political" (Yellow), from "Molecular, Biology and Immunology" to "Molecular, Biology and Genetics" (Orange), from "Economics, Economic and Political" to "Economics, Economic and Political" (Blue). Meanwhile, the largest circle in the source journal map represents many publications of EP are in ENERGY POLICY journals, which coordinates with the largest circle in the target journal map with the same discipline. Furthermore, the results reflecting from this dual-map overlay of journals (Figure 3) are in keeping with those shown in the Top 10 research directions (Figure 2), where the published articles on the theme of EP mainly focus on energy in society, science and engineering.

In addition, Tables 2 and 3 show some details about the Top 10 most productive journals and the Top 10 most cited documents, respectively.

Tab. 2. Top 10 most productive journals

\begin{tabular}{|c|c|c|c|c|}
\hline Rank & Journal & $\mathbf{T P}$ & TC & $\mathbf{A C}$ \\
\hline 1 & ENERGY POLICY & 232 & 2739 & 11.81 \\
\hline 2 & ENERGY RESEARCH \& SOCIAL SCIENCE & 101 & 768 & 7.60 \\
\hline 3 & RENEWABLE \& SUSTAINABLE ENERGY REVIEWS & 92 & 426 & 4.63 \\
\hline 4 & ENERGY AND BUILDINGS & 82 & 369 & 4.50 \\
\hline 5 & ENERGIES & 67 & 22 & 0.33 \\
\hline 6 & APPLIED ENERGY & $\mathbf{5 0}$ & 177 & 3.54 \\
\hline 7 & JOURNAL OF CLEANER PRODUCTION & 48 & 23 & 0.48 \\
\hline 8 & SUSTAINABILITY & 45 & 69 & 1.53 \\
\hline 9 & ENERGY & 45 & 187 & 4.16 \\
\hline 10 & ENERGY FOR SUSTAINABLE DEVELOPMENT & 33 & 220 & 6.67 \\
\hline
\end{tabular}

In Table 2, ten journals are ranked by the number of publications of EP. We can see that the most productive journal is ENERGY POLICY, which has published 232 relative documents and obtained the highest TC $(2,739$ times). The AC of this journal is 11.81, meaning that each publication from ENERGY POLICY is cited by 11-12 papers on average. This is followed by ENERGY RESEARCH \& SOCIAL SCIENCE, which has published 101 relevant articles, with the second-highest TC (768 times) and the second-highest AC (7.6 times). Similarly, the journal RENEWABLE \& SUSTAINABLE ENERGY REVIEWS ranks third, with 92 publications of EP and 426 total citations, but its AC (4.63 times) are not the third. From Table 3, it is reasonable to infer that TC and AC do not always correspond with the number of publications. More publications do not lead to higher citations, and fewer publications may result in higher AC. 
Tab. 3. Top 10 most cited documents

\begin{tabular}{|c|c|c|c|c|c|c|c|c|}
\hline Rank & Title & Authors & Type & Journal & $\begin{array}{l}\text { Research } \\
\text { direction }\end{array}$ & Year & $\mathbf{T C}$ & $\mathbf{A C}$ \\
\hline 1 & $\begin{array}{l}\text { Nano- } \\
\text { photocatalytic } \\
\text { Materials: } \\
\text { Possibilities and } \\
\text { Challenges }\end{array}$ & $\begin{array}{l}\text { Tong, Hua; } \\
\text { Ouyang, } \\
\text { Shuxin; Bi, } \\
\text { Yingpu; } \\
\text { Umezawa, } \\
\text { Naoto; } \\
\text { Oshikiri, } \\
\text { Mitsutake; } \\
\text { Ye, Jinhua }\end{array}$ & Review & $\begin{array}{l}\text { ADVANCED } \\
\text { MATERIALS }\end{array}$ & $\begin{array}{l}\text { Chemistry; } \\
\text { Science \& } \\
\text { Technology - } \\
\text { Other Topics; } \\
\text { Materials } \\
\text { Science; Physics }\end{array}$ & 2012 & 2575 & 286.11 \\
\hline 2 & $\begin{array}{l}\text { Polymeric } \\
\text { Photocatalysts } \\
\text { Based on } \\
\text { Graphitic Carbon } \\
\text { Nitride }\end{array}$ & $\begin{array}{l}\text { Cao, } \\
\text { Shaowen; } \\
\text { Low, } \\
\text { Jingxiang; } \\
\text { Yu, Jiaguo; } \\
\text { Jaroniec, } \\
\text { Mietek }\end{array}$ & Review & $\begin{array}{l}\text { ADVANCED } \\
\text { MATERIALS }\end{array}$ & $\begin{array}{l}\text { Chemistry; } \\
\text { Science \& } \\
\text { Technology - } \\
\text { Other Topics; } \\
\text { Materials } \\
\text { Science; Physics }\end{array}$ & 2015 & 1730 & 288.33 \\
\hline 3 & $\begin{array}{l}\text { Engineering } \\
\text { Carbon Materials } \\
\text { from the } \\
\text { Hydrothermal } \\
\text { Carbonisation } \\
\text { Process of } \\
\text { Biomass }\end{array}$ & $\begin{array}{l}\text { Hu, Bo; } \\
\text { Wang, Kan; } \\
\text { Wu, Liheng; } \\
\text { Yu, Shu- } \\
\text { Hong; } \\
\text { Antonietti, } \\
\text { Markus; } \\
\text { Titirici, } \\
\text { Maria- } \\
\text { Magdalena }\end{array}$ & Review & $\begin{array}{l}\text { ADVANCED } \\
\text { MATERIALS }\end{array}$ & $\begin{array}{l}\text { Chemistry; } \\
\text { Science \& } \\
\text { Technology - } \\
\text { Other Topics; } \\
\text { Materials } \\
\text { Science; Physics }\end{array}$ & 2010 & 1050 & 95.45 \\
\hline 4 & $\begin{array}{l}\text { Hydrogen } \\
\text { Evolution } \\
\text { Catalysed by } \\
\text { Cobaloximes }\end{array}$ & $\begin{array}{l}\text { Dempsey, } \\
\text { Jillian L.; } \\
\text { Brunschwig, } \\
\text { Bruce S.; } \\
\text { Winkler, Jay } \\
\text { R.; Gray, } \\
\text { Harry B. }\end{array}$ & Review & $\begin{array}{l}\text { ACCOUNTS OF } \\
\text { CHEMICAL } \\
\text { RESEARCH }\end{array}$ & Chemistry & 2009 & 702 & 58.5 \\
\hline 5 & $\begin{array}{l}\text { A review of } \\
\text { working fluid and } \\
\text { expander } \\
\text { selections for } \\
\text { organic Rankine } \\
\text { cycle }\end{array}$ & $\begin{array}{l}\text { Bao, } \\
\text { Junjiang; } \\
\text { Zhao, Li }\end{array}$ & Review & $\begin{array}{c}\text { RENEWABLE \& } \\
\text { SUSTAINABLE } \\
\text { ENERGY REVIEWS }\end{array}$ & $\begin{array}{c}\text { Science \& } \\
\text { Technology - } \\
\text { Other Topics; } \\
\text { Energy \& Fuels }\end{array}$ & 2013 & 673 & 84.13 \\
\hline 6 & $\begin{array}{l}\text { Metal-organic } \\
\text { frameworks as } \\
\text { platforms for } \\
\text { clean energy }\end{array}$ & $\begin{array}{l}\text { Li, Shun-Li; } \\
\text { Xu, Qiang }\end{array}$ & Review & $\begin{array}{c}\text { ENERGY \& } \\
\text { ENVIRONMENTAL } \\
\text { SCIENCE }\end{array}$ & $\begin{array}{l}\text { Chemistry; } \\
\text { Energy \& Fuels; } \\
\text { Engineering; } \\
\text { Environmental } \\
\text { Sciences \& } \\
\text { Ecology }\end{array}$ & 2013 & 649 & 81.13 \\
\hline 7 & $\begin{array}{l}\text { Combined } \\
\text { cooling, heating } \\
\text { and power: A } \\
\text { review }\end{array}$ & $\begin{array}{l}\text { Wu, D. W.; } \\
\text { Wang, R. Z. }\end{array}$ & Review & $\begin{array}{c}\text { PROGRESS IN } \\
\text { ENERGY AND } \\
\text { COMBUSTION } \\
\text { SCIENCE }\end{array}$ & $\begin{array}{l}\text { Thermodynamics; } \\
\text { Energy \& Fuels; } \\
\text { Engineering }\end{array}$ & 2006 & 518 & 34.53 \\
\hline 8 & $\begin{array}{l}\text { Dual role of } \\
\text { microalgae: } \\
\text { Phycoremediation } \\
\text { of domestic } \\
\text { wastewater and } \\
\text { biomass } \\
\text { production for } \\
\text { sustainable } \\
\text { biofuels } \\
\text { production }\end{array}$ & $\begin{array}{l}\text { Rawat, I.; } \\
\text { Kumar, R. } \\
\text { Ranjith; } \\
\text { Mutanda, T.; } \\
\text { Bux, F. }\end{array}$ & Article & APPLIED ENERGY & $\begin{array}{c}\text { Energy \& Fuels; } \\
\text { Engineering }\end{array}$ & 2011 & 510 & 51 \\
\hline 9 & $\begin{array}{l}\text { Graphene-Based } \\
\text { Photocatalysts for } \\
\text { Solar-Fuel } \\
\text { Generation }\end{array}$ & $\begin{array}{l}\text { Xiang, } \\
\text { Quanjun; } \\
\text { Cheng, Bei; } \\
\text { Yu, Jiaguo }\end{array}$ & Review & $\begin{array}{l}\text { ANGEWANDTE } \\
\text { CHEMIE- } \\
\text { INTERNATIONAL } \\
\text { EDITION }\end{array}$ & Chemistry & 2015 & 424 & 70.67 \\
\hline 10 & $\begin{array}{l}\text { Hydrogen the fuel } \\
\text { for } 21 \text { st century }\end{array}$ & Jain, I. P. & $\begin{array}{l}\text { Article, } \\
\text { Proceedings } \\
\text { Paper }\end{array}$ & $\begin{array}{c}\text { INTERNATIONAL } \\
\text { JOURNAL OF } \\
\text { HYDROGEN ENERGY }\end{array}$ & $\begin{array}{l}\text { Chemistry; } \\
\text { Electrochemistry; } \\
\text { Energy \& Fuels }\end{array}$ & 2009 & 382 & 31.83 \\
\hline
\end{tabular}

As shown in Table 3, 10 documents of EP are ranked by the number of citations. We can find that 9 of them are collaborative publications, except for the article and proceedings paper: "Hydrogen the fuel for $21^{\text {st }}$ century", which was written by one author I. P. Jain (2009). For the type of publications, 8 are reviews, and another 2 is an 
article and a proceedings paper. The most research directions of 10 publications are Chemistry, Science \& Technology - Other Topics, Materials Science or Physics, and there are also researches concerning Energy \& Fuels, Engineering, Environmental Sciences \& Ecology, Thermodynamics and Electrochemistry. All of them are cited more than 300 times, and the top 3 publications are cited more than 1,000 times. And the top 10 publications were published during the period of 2006-2015. It is noted that the top 4 documents are focused on chemistry or materials, that is because some chemical materials, for example, semiconductor photocatalysis or Cobaloximes, are considered to be attractive ways for solving the worldwide energy shortage and environmental pollution issues. These documents focus on the scientific and technological possibilities offered by materials, providing state-ofthe-art research activities and in the field of energy poverty.

\section{Where and who pay more attention to EP?}

It is obvious that many researchers from different countries/regions are interested in EP, so we analyse the published papers from three perspectives: countries/regions, institutions, and authors.

\section{The most productive countries/regions}

The number of published documents is one of the important indicators to reflect the popular degree of a certain research theme in a country/region. In Figure 4, we display TP on the theme of EP in different countries/regions on the world map. The darker the brownish red, the more publications the country/region has.

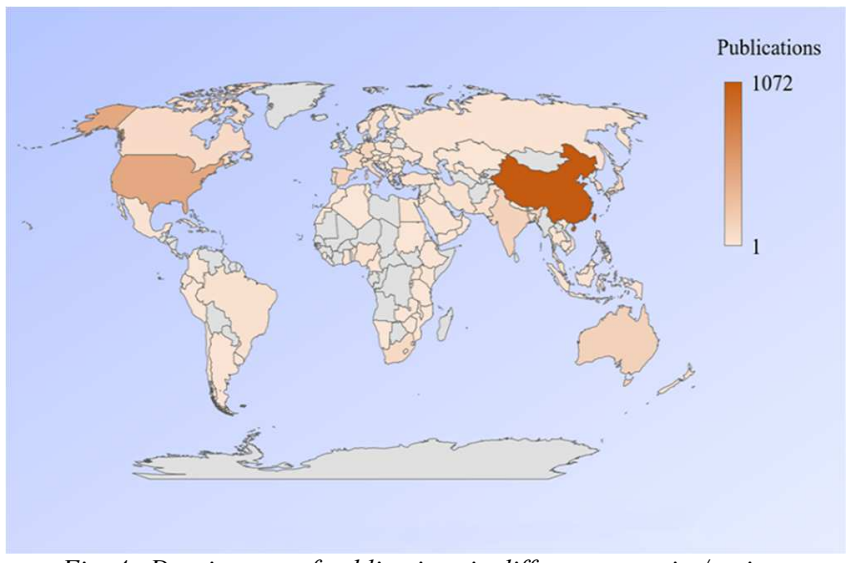

Fig. 4. Density map of publications in different countries/regions

From Figure 4, we know that in terms of EP, China is the most productive country around the world, with 1,072 publications. The second one is the USA with 460 publications, and the third one is the UK with 390 publications. Followed by, is Australia (150 publications) and India (142 publications), respectively.

Figure 5 exhibits cooperation relationships among countries/regions. In VOS viewer, by setting the maximum number of countries/regions per document as 25 and the minimum number of documents per country/region as 5 , 65 of 110 countries/regions meet the threshold, and the largest close-connected network is selected consisting of 64 items, which compose the cooperation network.

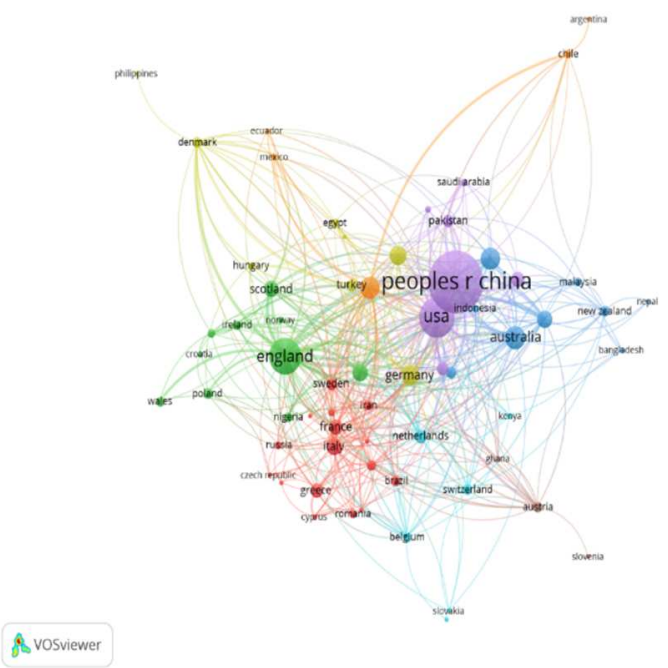

Fig. 5. Cooperation network of countries/regions 
As we can see, the People's Republic of China (China) has the most cooperation with other countries/regions (1,067 times), the second is the USA (445 times), and the third is England (UK) (380 times). Their cooperation with others is displayed in Figure 6. To be specific, China has the closest connection with USA, Australia and UK. Similarly, the USA connects China, UK and India deeply; the UK is tightly linked to China, USA and Scotland.

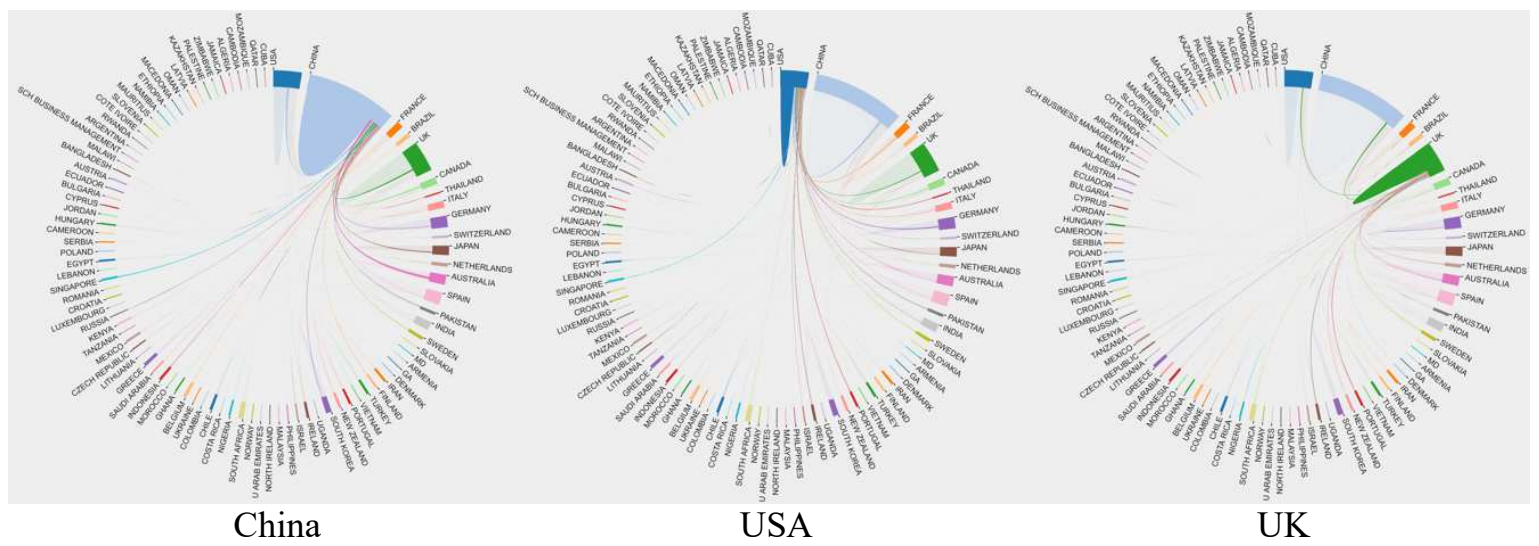

Fig. 6. Cooperation network of China, USA and UK

\section{The most influential institutions}

The number of citations and cooperation conditions reflect the impact of institutions. 245 of 2,906 institutions have published at least 5 documents, and 230 of them form the largest connected network, shown in Figure 7.

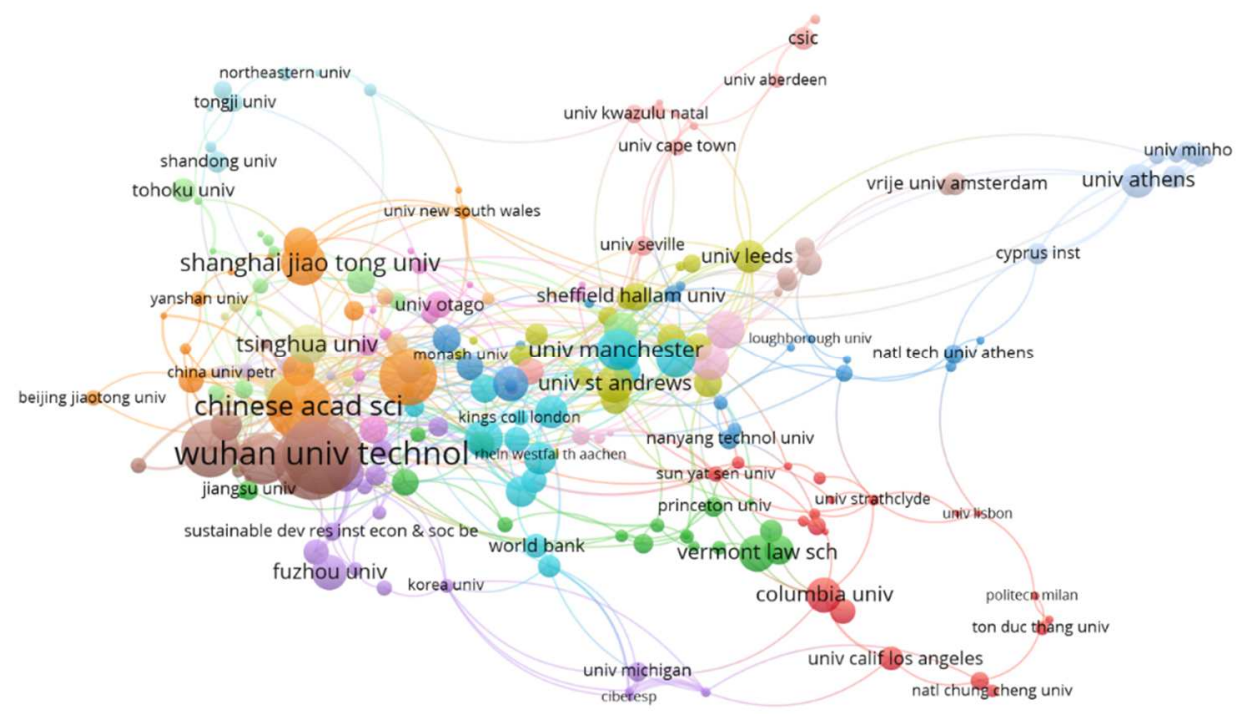

\& VOSviewer

Fig. 7. Cooperation network of institutions

230 institutions have been classified into 18 clusters which are differentiated by 18 colours. The size of each node is set as the number of citations of each institution, and the larger the node, the more citations the institution received. In addition, the link between two nodes signifies that there is a connection, and the width of the link is on behalf of link strength, that is the frequency of cooperation. As is shown in Figure 7, WUHAN UNIV TECHNOL has received the maximum number of citations. For further study of the citation and connection relationship of these institutions, Top 6 most influential institutions and their strongest cooperation relationship are displayed in Table 4. 
Tab. 4. Top 6 most influential institutions and their strongest cooperation relationship

\begin{tabular}{|c|c|c|c|c|c|c|c|c|}
\hline \multirow[b]{2}{*}{ Rank } & \multirow[b]{2}{*}{ Institution } & \multirow[b]{2}{*}{ TC } & \multirow[b]{2}{*}{$\mathbf{T P}$} & \multirow[b]{2}{*}{ Link } & \multirow[b]{2}{*}{$\begin{array}{l}\text { Total link } \\
\text { strength }\end{array}$} & \multicolumn{3}{|c|}{ Main cooperators } \\
\hline & & & & & & Institution & $\begin{array}{c}\text { Link } \\
\text { Strength } \\
\end{array}$ & $\begin{array}{c}\text { Cooperation } \\
\text { strength } \\
\end{array}$ \\
\hline 1 & $\begin{array}{l}\text { WUHAN UNIV } \\
\text { TECHNOL } \\
\text { KING }\end{array}$ & 2882 & 22 & 10 & 16 & KING ABDULAZIZ UNIV & 6 & $37.5 \%$ \\
\hline 2 & $\begin{array}{l}\text { ABDULAZIZ } \\
\text { UNIV }\end{array}$ & 2706 & 9 & 6 & 11 & WUHAN UNIV TECHNOL & 6 & $54.55 \%$ \\
\hline 3 & $\begin{array}{c}\text { CHINESE ACAD } \\
\text { SCI }\end{array}$ & 1926 & 81 & 37 & 70 & UNIV CHINESE ACAD SCI & 17 & $24.29 \%$ \\
\hline & & & & & & $\begin{array}{c}\text { DALIAN UNIV TECHNOL } \\
\text { NORTH CHINA ELECT } \\
\text { POWER UNIV } \\
\text { TSINGHUA UNIV } \\
\text { MINIST EDUC }\end{array}$ & $\begin{array}{l}1 \\
1 \\
1 \\
1\end{array}$ & $\begin{array}{l}9.09 \% \\
9.09 \% \\
9.09 \% \\
9.09 \%\end{array}$ \\
\hline 4 & TIANJIN UNIV & 1510 & 23 & 11 & 11 & $\begin{array}{c}\text { BEIJING UNIV CHEM } \\
\text { TECHNOL } \\
\text { CHINESE ACAD SCI } \\
\text { TIANJIN UNIV TECHNOL } \\
\text { UNIV QUEENSLAND } \\
\text { UNIV TOKYO } \\
\text { JILIN UNIV }\end{array}$ & $\begin{array}{l}1 \\
1 \\
1 \\
1 \\
1 \\
1\end{array}$ & $\begin{array}{l}9.09 \% \\
9.09 \% \\
9.09 \% \\
9.09 \% \\
9.09 \% \\
9.09 \%\end{array}$ \\
\hline 5 & $\begin{array}{c}\text { UNIV SCI \& } \\
\text { TECHNOL CHINA }\end{array}$ & 1492 & 22 & 9 & 20 & CHINESE ACAD SCI & 8 & $40 \%$ \\
\hline & $\begin{array}{l}\text { NATL UNIV } \\
\text { SINGAPORE }\end{array}$ & 1195 & 24 & 6 & 6 & $\begin{array}{c}\text { CHONGIQNG UNIV } \\
\text { NANJING TECH UNIV } \\
\text { SOUTHWESTERN UNIV } \\
\text { FINANCE \& ECON } \\
\text { HARVARD UNIV } \\
\text { GEORGIA INST TECHNOL } \\
\text { CENT S UNIV }\end{array}$ & $\begin{array}{l}1 \\
1 \\
1 \\
1 \\
1 \\
1\end{array}$ & $\begin{array}{l}16.67 \% \\
16.67 \% \\
16.67 \% \\
16.67 \% \\
16.67 \% \\
16.67 \%\end{array}$ \\
\hline
\end{tabular}

The six most influential institutions are sorted by the number of citations. Among them, four institutions are from China, and others are from Saudi Arabia and Singapore, respectively. WUHAN UNIV TECHNOL has a very strong cooperation relationship with KING ABDULAZIZ UNIV from the first and the second rows of Table 4. CHINESE ACAD SCI has the closest partnership with UNIV CHINESE ACAD SCI. TIANJIN UNIV has deep cooperation with ten institutions, such as DALIAN UNIV TECHNOL, NORTH CHINA ELECT POWER UNIV and TSINGHUA UNIV. Similarly, NATL UNIV SINGAPORE also cooperates with six institutions with equal link strength, for example, CHONGIQNG UNIV, NANJING TECH UNIV and SOUTHWESTERN UNIV FINANCE \& ECON. In conclusion, academic institutions worldwide in-deep cooperation with each other, focusing on EP and promoting its development.

\section{The most influential authors}

The identification of the most influential authors will provide useful instruction for other scholars who are about to enter this field. We first draw the citation network of authors in Figure 8. According to VOS viewer, 10,395 authors have published relative papers about this topic, and 336 of them published over three documents.

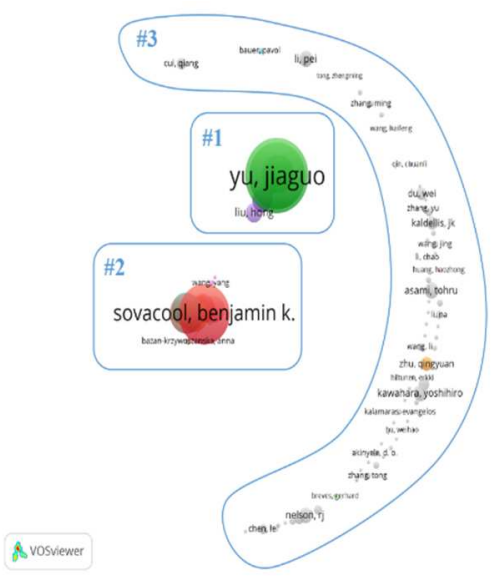

Fig. 8. Citation network of authors 
All authors focusing on EP can be classified into three blocks. Authors in \#1 mainly study EP from aspects of chemistry or materials, especially in photocatalysis, and they often discover or invent new substances to carry or produce energy for countering EP (refer to Clusters \#3 and \#4 in Section 3.3). While authors in \#2 pay more attention to the EP in the social, environmental, or economic field. They usually study the energy in society and propose some new methods or policies to counter EP (refer to Clusters \#0 and \#2 in Section 3.3). Moreover, authors in \# 3 are from other research fields, which focus on EP in electricity, engineering or others (refer to Cluster \#1 in Section 3.3). We can see that authors in the same block have close cooperation while there is almost no connection between authors in different blocks. That is because the researchers interested in EP are from various fields. For more details, we show Top 10 most influential authors in Table 5.

Tab. 5. Top 10 most influential authors

\begin{tabular}{|c|c|c|c|c|c|c|c|}
\hline Rank & Author & Country/Region & Block & TC & TP & $\overline{\mathrm{AC}}$ & Total link strength \\
\hline 1 & Yu, Jiaguo & China & $\# 1$ & 2637 & 6 & 439.5 & 47 \\
\hline 2 & Cao, Shaowen & China & $\# 1$ & 2138 & 4 & 534.5 & 36 \\
\hline 3 & Sovacool, Benjamin K. & USA & $\# 2$ & 1790 & 39 & 45.8974 & 370 \\
\hline 4 & Bouzarovski, Stefan & UK & $\# 2$ & 844 & 20 & 42.2 & 981 \\
\hline 5 & Cheng, Bei & China & $\# 1$ & 766 & 4 & 191.5 & 29 \\
\hline 6 & Mccauley, Darren & Scotland & $\# 2$ & 584 & 8 & 73 & 167 \\
\hline 7 & Healy, Jd & Ireland & $\# 2$ & 540 & 5 & 108 & 201 \\
\hline 8 & Day, Rosie & UK & \#2 & 492 & 10 & 49.2 & 306 \\
\hline 9 & Li, Zhaohui & China & $\# 1$ & 473 & 5 & 94.6 & 17 \\
\hline 10 & Pachauri, Shonali & Austria & $\# 2$ & 461 & 9 & 51.2222 & 109 \\
\hline
\end{tabular}

The top 10 most influential authors are ranked by TC. Yu, Jiaguo is the most influential author (2,637 citations) from China, and followed by is Cao, Shaowen (2,138 citations) from China, Sovacool, Benjamin K. (1,790 citations) from USA and Bouzarovski, Stefan (844 citations) from the UK. It is noted that all top 10 most influential authors are from Block \#1 and Block \#2, which also confirm the popularity and influence of EP in research fields of chemistry/materials, environment/engineering/economics.

The Cooperation network of authors clearly reflects the connection of researchers in this field. In VOS viewer, the size of a node represents the number of documents the author cooperated with others, and the width of a link demonstrates the cooperation strength of two connected authors who cooperated with others. By setting the maximum number of authors per document as 25 and an author published at least 3 documents, 336 of 10,395 authors meet the thresholds, and among them, 42 authors constitute the largest set of a connected network, which is shown in Figure 9.

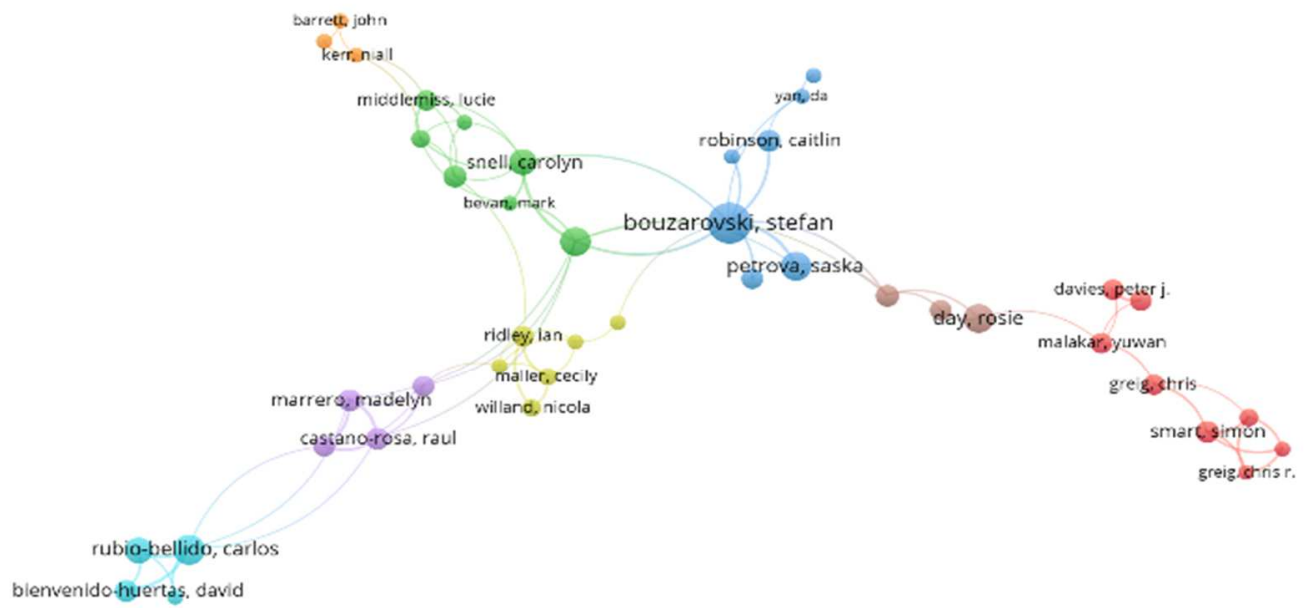

VOSviewer

(a) 


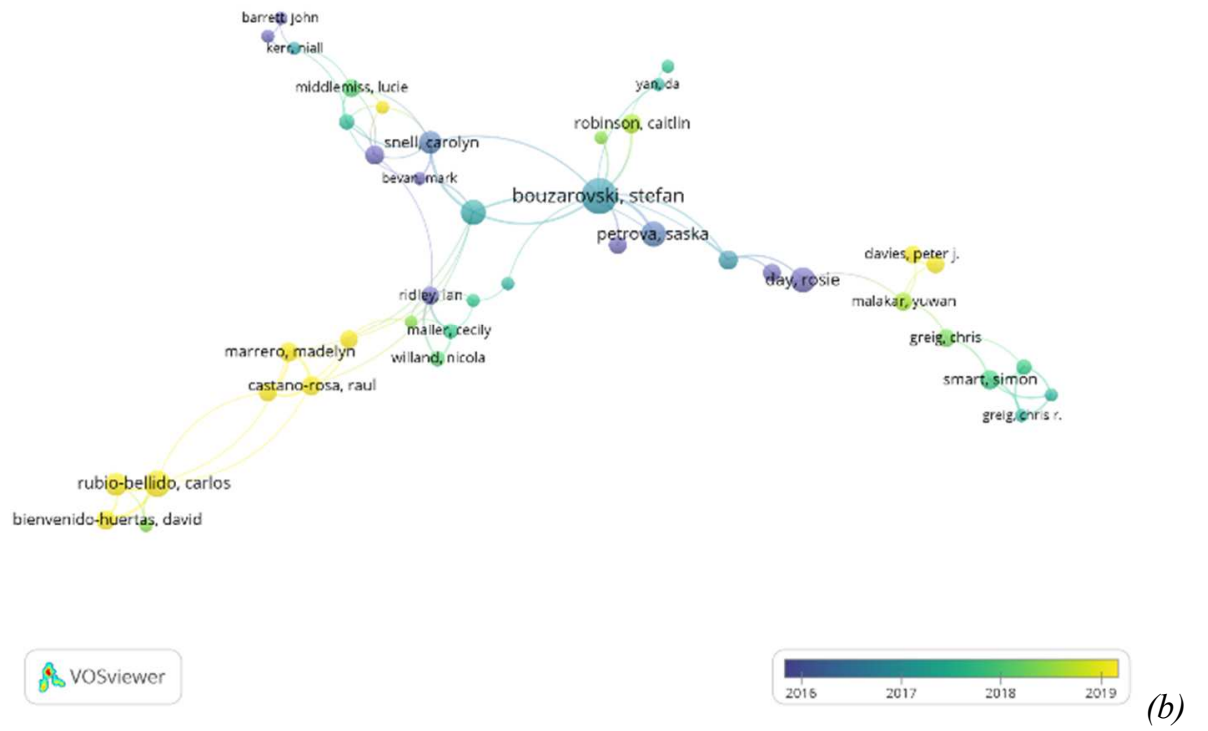

Fig. 9. (a) Cooperation network of authors and (b) Cooperation network of authors with the timeline

From Figure 9(a), we know that authors are classified into eight clusters in the closest cooperation network. Bouzarovski Stefan, from the UK, cooperates most with other people and has a deep cooperation relationship with Petrova Saska, who is from the UK. Rubio-Bellido Carlos, coming from Spain, is also a frequent collaborator, and Perez-Fargallo Alexis from Chile is his main partner. From Figure 9(b), we can see how authors collaborate at different times. The gradient of colours in the map changes from purple to yellow. Purple nodes are authors who collaborate relatively early, while yellow nodes are authors who collaborate relatively late. Marrero Madelyn, Rubio-Bellido Carlos, Davis Peter J, Hargreaves Tom and their key collaborators have recently come together to explore EP.

\section{Theme analysis through keywords}

Theme analysis is one of the most important tasks in subject bibliometric analysis, and keywords reflect most of the contents in the theme (Chen, 2017). In what follows, the theme is analysed based on keywords from four aspects: keyword-burst detection, landscape view, timeline visualisation and major specialities.

\section{Keyword-burst detection}

According to the results shown in CiteSpace, major milestones in the development of EP can be identified from the list of keywords that have strong citation bursts from 1942 to 2020 (shown in Figure 10).

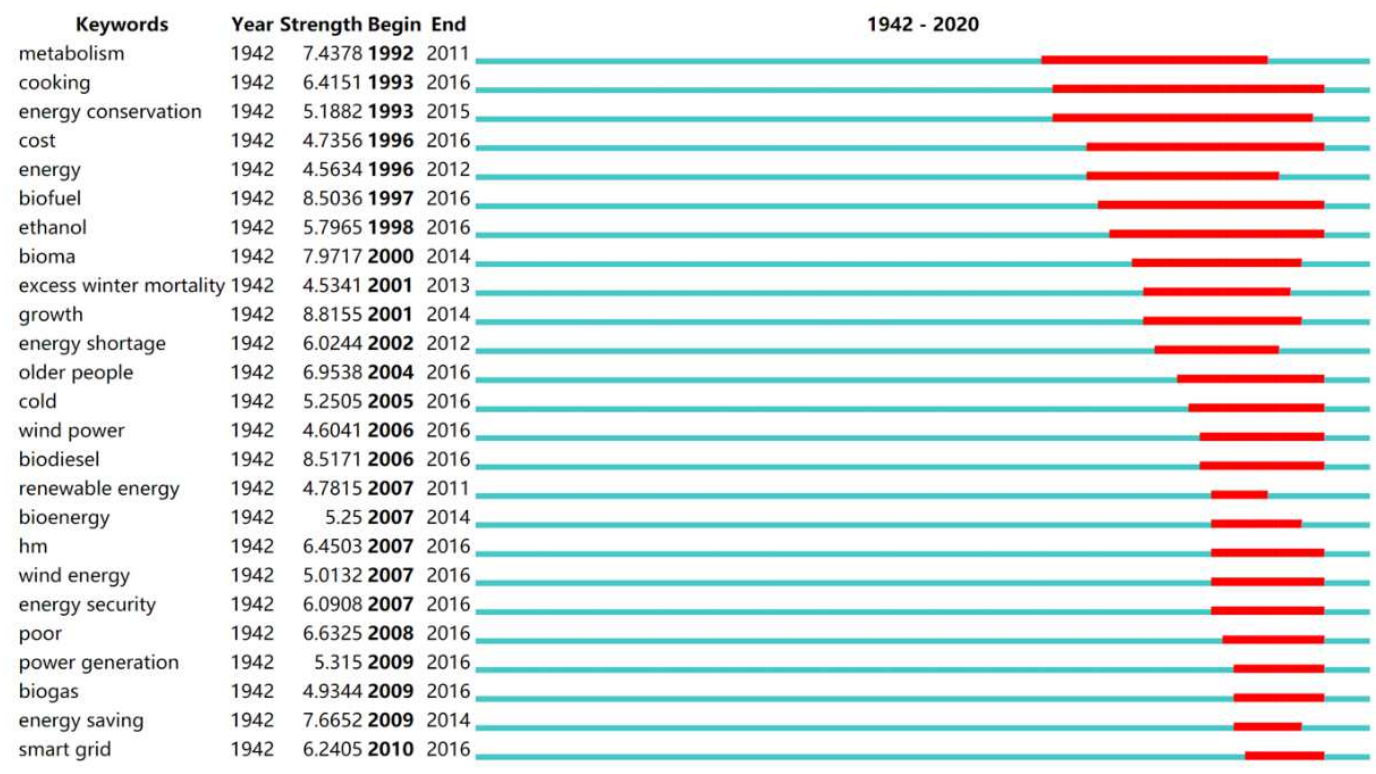

Fig. 10. Top 25 keywords with the strongest citation burst ranked by beginning year 
Keywords with strong values in the Strong column means to be significant milestones of EP, which is ranked by the beginning year. We pay more attention to these keywords. For example, metabolism was the first keyword to be detected by burst, which can be seen in (Schrodervanderelst and Vanderheide, 1992) and (Leister et al., 2011), cooking (Herington and Malakar, 2016) has occupied the longest time with twenty-four years in the keywork-burst detection while renewable energy (Bhide and Rodriguez Monroy, 2011) only lasted five years. Many keywords such as cost and biofuel played an important role until 2016, while the smart grid (Kuang et al., 2016) was the upto-date milestone and had been arising wide public concerns.

\section{Landscape view}

The following landscape view is visualised on CiteSpace, based on articles published between 1942 and 2020. The top $15 \%$ of most-cited publications in each twenty-five years are used to construct a clustering network of keywords (shown in Figure 11).

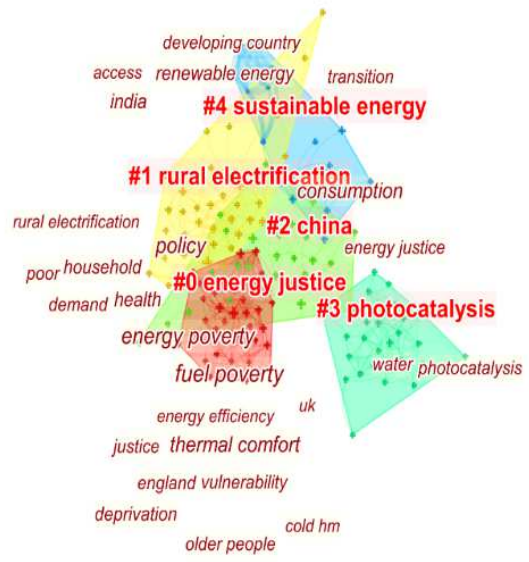

Fig. 11. A landscape view of the keyword co-occurrence network

The clustering network has a modularity of 0.6556 , which is considered high, suggesting that the specialities in EP are clearly defined in terms of clusters. The weighted mean silhouette score of 0.869 is very high, meaning that we got a convincing clustering result. Then, 188 selected keywords are divided into five clusters which are numbered from 0, i.e. Cluster \#0 is the largest cluster, and Cluster \#1 is the second largest one. Cluster \#0 is labeled as "Energy justice", Cluster \#1 is labeled as "Rural electrification", Cluster \#2 is labeled as "China", Cluster \#3 is labeled as "Photocatalysis", and Cluster \#4 is labeled as "Sustainable Energy". This keyword clustering network is very important, which can be used to analyse the following timeline visualisation and major specialities.

\section{Timeline visualisation}

A timeline visualisation of EP in CiteSpace depicts the above five clusters along with horizontal timelines (shown in Figure 12). All clusters are displayed from left to right, and the keywords in each cluster are presented on the timeline when they first appeared. The legend of published time is shown on the top of the view, and all clusters are arranged vertically in order of size from largest to smallest. The size of each node represents the citations the corresponding keyword has, and the large-sized nodes or nodes with red rings are of particular interest because they are either frequently used or have citation bursts or both. Only some landmark keywords of each cluster are exhibited according to bursts and citations (Figure 12), and all of the keywords within every cluster will be shown completed in Section 3.3.4 (See Figures 13, 15, 17, 19, 21).

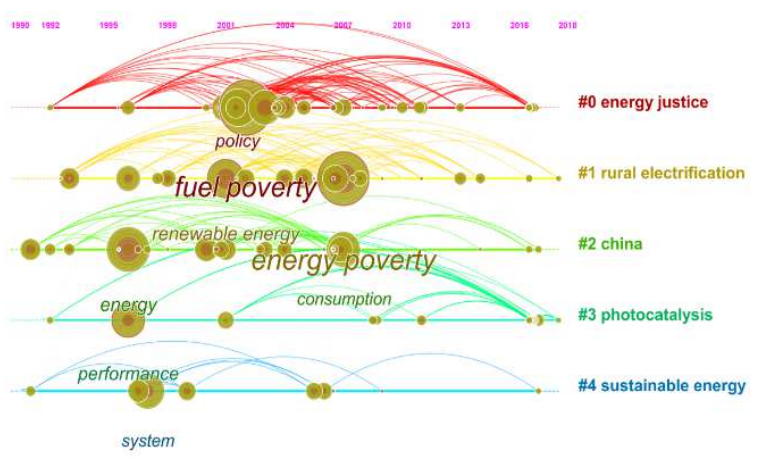

Fig. 12. A timeline visualisation of all clusters (Landmark keywords are labelled) 
Cluster \#0 appeared in about 1992 and developed quickly from 2000 to 2007, and then it started to cool down from 2016. Fuel poverty is the highest burst keyword, and policy has the second most citation. In Cluster \#1, the first publication concerning rural electrification appeared after 1992. From 2001 to 2008, the cluster aroused wide interest among scholars worldwide, and it is still a popular research field. Both Energy poverty and renewable energy have highly burst citations, and they are significant terms in this cluster. Many people paid attention to Cluster \#2 around 1991, and the concerns lasted for about twenty-six years. Researchers were most concerned about the theme of energy and consumption. Cluster \#3 started in 1992, and it cared about chemical reactions regarding to EP so that the keyword performance was highly cited. Similarly, Cluster \#4 began in about 1990 and was more focused on the keyword system.

\section{Major specialities}

In the following discussions, we will particularly focus on the major speciality in each cluster (Table 6). A research field can be characterised by an intellectual base and research front, where the intellectual base is a collection of works that have been cited by the research community, and the research front is composed of citing articles that are motivated by an intellectual base (Chen, 2017). Hence, the keywords in cited references and citing articles can reflect the major speciality of each cluster.

Tab. 6. Cluster information summary list

\begin{tabular}{|c|c|c|c|c|}
\hline Cluster ID & Size & Silhouette & Mean (Year) & Top 5 keywords in citing articles ranked by LLR \\
\hline 0 & 36 & 0.841 & 2006 & $\begin{array}{c}\text { Energy justice } \\
\text { Energy efficiency } \\
\text { Thermal comfort } \\
\text { Overheating } \\
\text { Retrofit }\end{array}$ \\
\hline 1 & 35 & 0.856 & 2005 & $\begin{array}{c}\text { Rural electrification } \\
\text { Energy poverty } \\
\text { Adoption } \\
\text { Transition } \\
\text { Rural energy }\end{array}$ \\
\hline 2 & 27 & 0.764 & 2002 & $\begin{array}{c}\text { China } \\
\text { Biorefinery } \\
\text { Energy consumption } \\
\text { Biodiesel } \\
\text { Income }\end{array}$ \\
\hline 3 & 26 & 0.977 & 2012 & $\begin{array}{c}\text { Photocatalysis } \\
\text { CO2 reduction } \mathrm{CO} 2 \\
\text { Energy poverty } \\
\text { Photocatalytic reduction } \\
\text { Nanocomposite }\end{array}$ \\
\hline 4 & 16 & 0.96 & 1998 & $\begin{array}{c}\text { Sustainable energy } \\
\text { Solar energy } \\
\text { Energy poverty } \\
\text { Equations } \\
\text { Thermal }\end{array}$ \\
\hline
\end{tabular}

The cluster ID is ranked by the number of keywords collected from the cited reference in each cluster. We can see that every cluster has more than 15 keywords. The silhouette value of each cluster is over 0.75 , meaning that all clusters are convinced. Moreover, the label of each cluster is selected by the log-likelihood ratio (LLR) test method and is named as the keyword with the first LLR value. To exhibit more information of each cluster, Top 5 keywords with the highest LLR value in citing articles are shown in Table 6.

\section{Cluster \#0 - Energy justice}

Cluster \#0 is the largest cluster containing 36 keywords selected from cited references. The median year of all keywords within this cluster is 2006, and the silhouette value of this cluster is 0.841 , which both take the middle position of all clusters. According to the top 5 keywords in Table 6, we know that Cluster \#0 is concerned with some EP assessment indicators or policies such as energy justice, energy access or energy efficiency.

The timeline view reveals the development of Cluster \#0 (Figure 13). The first period is from 1992 to 2001. This period is relatively uneventful without keywords in terms of citation counts or bursts. Among all keywords, the $U K$ is the most cited. That is because the concept of EP was introduced in the UK in 1979 due to the petroleum crisis (Isherwood and Hancock, 1979). Also, in the UK, the definition of EP was given for the first time in 1991 as the occasion when households cannot "have adequate energy services for 10 per cent of income" (Boardman, 2010). Then, some researchers from the UK continued to study EP (Jones, 2001). The second period is from 2001 to 2007. Unlike the first period, this one has a large number of high-impact keywords, such as thermal comfort, policy and energy efficiency. Especially, the keyword fuel poverty has the largest citation tree-ring and a period of citation bursts coloured in red, which reflects that fuel poverty is one of the main expressive forms of EP (Dubois 
and Meier, 2016). The third period is from 2008 to 2018, when the evaluation indicators of energy vulnerability, such as energy justice, is studied comprehensively (Castano-Rosa et al., 2019).

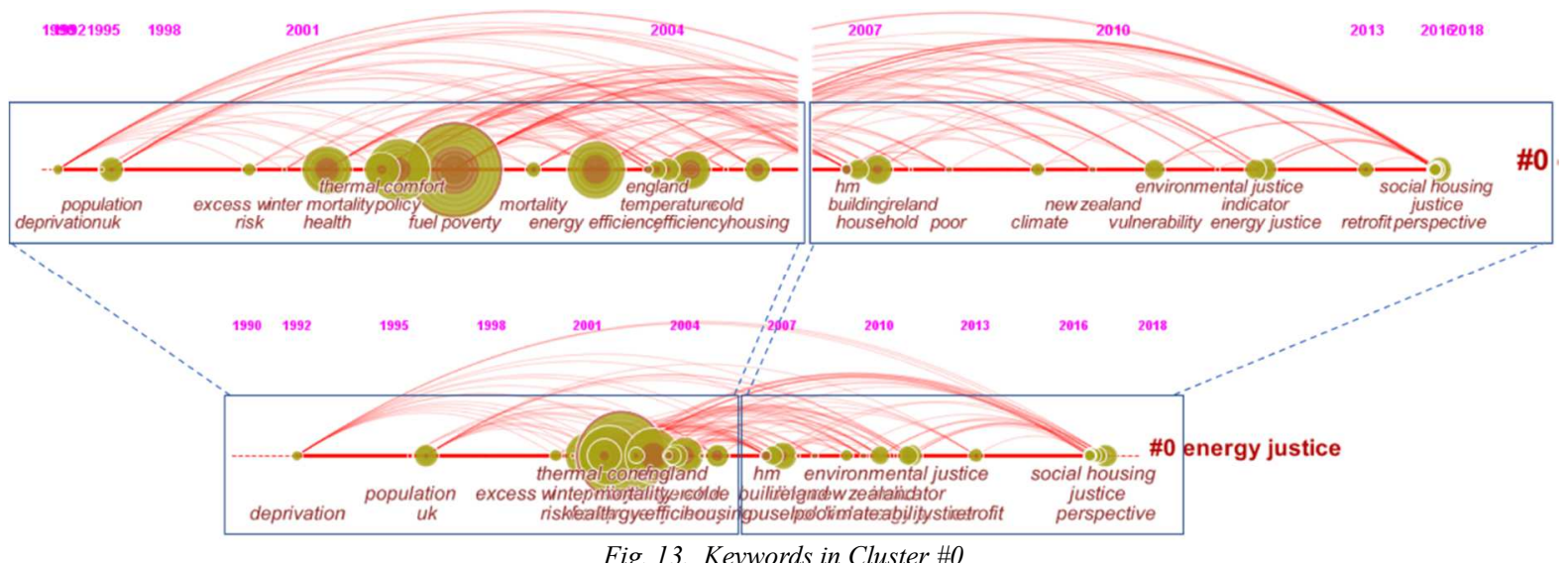

Keywords in cited references lay a solid foundation for the research community even for further citing articles. They can complement some basic knowledge for understanding the development of specialities. Shown in Figure 14, the top 20 keywords of cited references in Cluster\#0 ranked by Sigma represent that scholars in early years have paid close attention to justice, social housing and poverty. The value of Sigma is calculated based on the values of centrality and emergent. The keyword with higher centrality and emergent will have a higher sigma value, and the keyword with higher Sigma is more important in the structure of articles and citation change (Chen, 2017).

\begin{tabular}{|r|r|r|r|c|l|}
\hline Freq & Burst & Degree & Centrality & $\Sigma$ & \multicolumn{1}{|c|}{ Keyword } \\
\hline 41 & 6.05 & 14 & 0.02 & 1.14 & justice \\
\hline 30 & 5.54 & 8 & 0.02 & 1.12 & social housing \\
\hline 18 & 6.63 & 14 & 0.01 & 1.08 & poor \\
\hline 17 & 6.22 & 13 & 0.01 & 1.03 & cold hm \\
\hline 20 & 6.95 & 14 & 0.00 & 1.02 & older people \\
\hline 18 & 6.45 & 12 & 0.00 & 1.02 & hm \\
\hline 54 & 3.95 & 11 & 0.00 & 1.01 & perspective \\
\hline 98 & & 17 & 0.02 & 1.00 & household \\
\hline 11 & 4.29 & 10 & 0.00 & 1.00 & new zealand \\
\hline 37 & & 15 & 0.02 & 1.00 & england \\
\hline 11 & 4.53 & 6 & 0.00 & 1.00 & excess winter mortality \\
\hline 51 & & 15 & 0.01 & 1.00 & vulnerability \\
\hline 24 & & 5 & 0.00 & 1.00 & europe \\
\hline 128 & & 19 & 0.01 & 1.00 & health \\
\hline 48 & & 12 & 0.01 & 1.00 & building \\
\hline 458 & & 37 & 0.14 & 1.00 & fuel poverty \\
\hline 36 & & 10 & 0.10 & 1.00 & retrofit \\
\hline 56 & & 11 & 0.08 & 1.00 & temperature \\
\hline 31 & & 8 & 0.00 & 1.00 & climate \\
\hline 46 & & 10 & 0.01 & 1.00 & housing \\
\hline
\end{tabular}

Fig. 14. Top 20 Keywords of cited references in Cluster\#0, ranked by Sigma

According to the analysis of keywords in citing articles and cited references, Cluster \#0 mainly focuses on assessment indicators or policy of EP. After the concept of EP was proposed (Isherwood and Hancock, 1979), some researchers began to study energy justice in the developed countries such as the UK or other European countries (Martiskainen and Sovacool, 2020; Streimikiene et al., 2020), while other researchers from the developing or underdeveloped countries would rather study the energy access which is more suitable for evaluating the status of energy use for the poor in practice (Yadava and Sinha, 2019; Gebreslassie, 2020). Then, energy efficiency and multiple indicators were proposed to enrich the assessment method and policy for EP (CastanoRosa et al., 2019).

\section{Cluster \#1 - Rural electrification}

Cluster \#1 is the second-largest cluster, including 35 keywords selected from cited references. The median year of all keywords is 2005, and the silhouette value of this cluster is 0.856 , which explains that the cluster's content is convincing. The primary focus of this cluster is on the status and development of electricity or renewable energy in rural areas and the developing countries. 
All keywords of Cluster \#1 are exhibited clearly in the timeline view (Figure 15). The development of this cluster can be divided into three periods. 1992 to 2000 is the first period in which the research community mainly studied the energy conservation or electricity in developing countries (Palanichamy et al., 1999) or constructed multiple models to analyse the impact of EP. The second period is from 2001 to 2008, during which the cluster was flourishing, and many highly cited keywords led the direction of the research field. For example, many people paid more attention to renewable energy (Su et al., 2008) and the sustainable development of rural electrification (Singal et al., 2007). The keyword EP played an important role in Cluster \#1. The third phase is from 2009 to the present, electrification access and energy transition have aroused great research concerns (Hamburger et al., 2019).

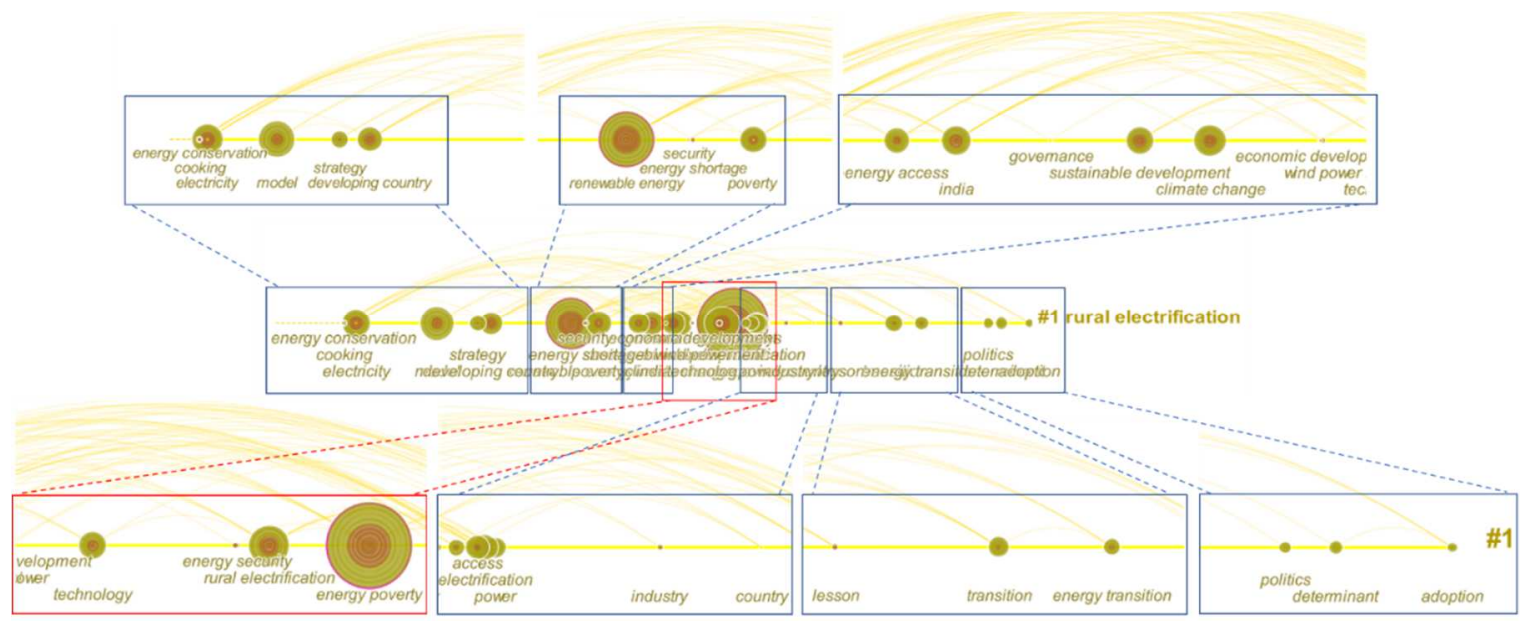

Fig. 15. Keywords in Cluster \#1

The keywords in the cited references provide extra information for recognising the specialities of the same cluster. As shown in Figure 16, renewable energy, wind power, cooking, energy conservation and rural electrification are the top 5 keywords based on the Sigma value, and many terms in Figure 16 are consistent with those in Table 6 and Figure 15, which confirm the above analysis and build a connection among the citing articles and the cited references. Furthermore, some keywords, such as Africa and challenge, provide more information for speciality analysis.

\begin{tabular}{|r|r|r|r|c|l|}
\hline Freq & Burst & Degree & Centrality & $\Sigma$ & \multicolumn{1}{|c|}{ Keyword } \\
\hline 213 & 4.78 & 20 & 0.14 & 1.88 & renewable energy \\
\hline 13 & 4.60 & 3 & 0.03 & 1.17 & wind power \\
\hline 19 & 6.42 & 9 & 0.02 & 1.13 & cooking \\
\hline 14 & 5.19 & 2 & 0.02 & 1.09 & energy conservation \\
\hline 99 & 5.58 & 13 & 0.01 & 1.04 & rural electrification \\
\hline 56 & 4.39 & 6 & 0.00 & 1.02 & sustainable development \\
\hline 11 & 4.29 & 5 & 0.00 & 1.01 & country \\
\hline 11 & 4.47 & 7 & 0.00 & 1.01 & lesson \\
\hline 10 & & 2 & 0.00 & 1.00 & industry \\
\hline 58 & & 14 & 0.05 & 1.00 & developing country \\
\hline 22 & & 5 & 0.00 & 1.00 & adoption \\
\hline 72 & & 18 & 0.02 & 1.00 & india \\
\hline 54 & & 13 & 0.01 & 1.00 & access \\
\hline 81 & & 11 & 0.02 & 1.00 & poverty \\
\hline 42 & & 8 & 0.00 & 1.00 & africa \\
\hline 62 & & 10 & 0.00 & 1.00 & energy access \\
\hline 12 & 4.20 & 2 & 0.00 & 1.00 & governance \\
\hline 91 & & 11 & 0.01 & 1.00 & electricity \\
\hline 11 & & 2 & 0.00 & 1.00 & economic development \\
\hline 30 & & 1 & 0.00 & 1.00 & challenge \\
\hline
\end{tabular}

Fig. 16. Top 20 Keywords of cited references in Cluster\#1, ranked by Sigma

EP and lack of electricity in rural areas exacerbate the poverty of the developing countries, so that renewable energy, for example, wind power, solar power and hydropower, could be a potential solution for rural electrification (Borhanazad et al., 2013). Thus, Cluster \#1 plays a significant role in all clusters as it focuses on the current situation and development of rural electrification and proposes some great policies or effective measures to reduce the EP of the rural area. 


\section{Cluster \#2 - China}

27 keywords collected from cited references are included in Cluster \#2. The silhouette value of this cluster is 0.764 , and the median year of all keywords is 2002 . According to keywords in Table 6, Cluster \#2 takes China as an example to analyse the impact of energy consumption, EP, energy access and energy security on economic growth, environmental assessment and social development all over the world, especially in the developing or underdeveloped countries. Sustainable biomass fuels production will be a feasible option for fuel shortage.

The timeline view records two development periods of Cluster \#2 (Figure 17). The first period, from 1990 to 2007, includes ages of creativity and prosperity. Starting from the keyword China, the first period contained many high-impact keywords like energy, biomass, impact and consumption. In many rural areas of the developing countries, poor people still depend on wood and other simple biomass fuels for their daily household and indoor warm, and they spend too much time in doing time-consuming households so that disproportionate lack of access to education and income, which has a profound impact on economic, social, and environmental development (Sesan, 2012; Kaygusuz, 2011). Although biomass resources in some countries like China are abundant, the technology for biomass resource conversion in China is still just beginning (Tan et al., 2010). Thus, numerous types of renewable biomass energy and corresponding advanced generation technology can be an ideal choice to reduce EP and provide energy for future social and economic development. The second period begins with 2008, and just a few keywords are displayed in the timeline view like coal, $\mathrm{CO}_{2}$ emission and income. Conventional energy consumption like coal may lead to excessive $\mathrm{CO}_{2}$ emission, so that many countries have started to explore renewable fuels or levy a carbon tax (Tsai et al., 2011).

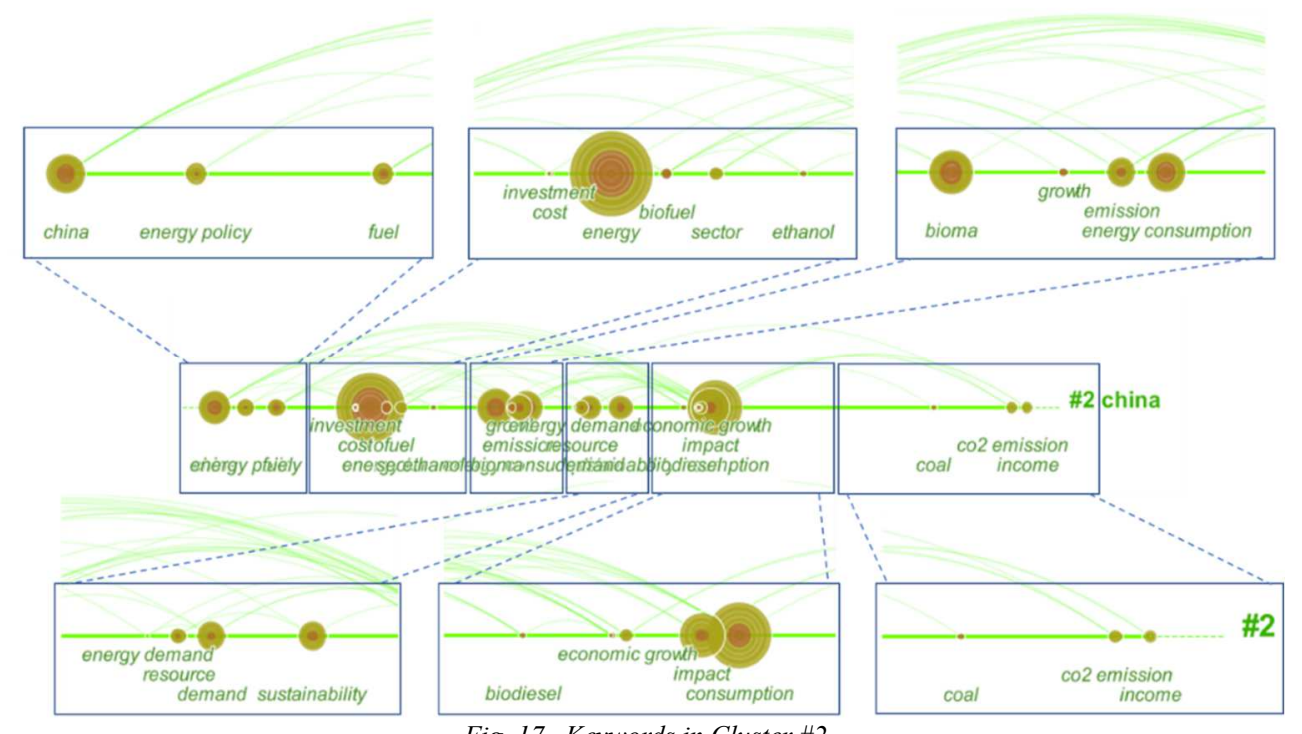

Fig. 17. Keywords in Cluster $\# 2$

Keywords of cited references in Cluster \#2 provide a knowledge basis for the collected articles. In Figure 18, it is obvious that four of the top six keywords are related to biomass fuels, and the rest are energy and coal. Nineteen of twenty keywords are the same as those in Figure 18, which verifies the validity of the keywords shown in Figure 17.

\begin{tabular}{|r|r|r|r|l|l}
\hline Freq & Burst & Degree & Centrality & $\Sigma$ & \multicolumn{1}{|c}{ Keyword } \\
\hline 221 & 4.56 & 5 & 0.09 & 1.48 energy \\
\hline 25 & 8.50 & 7 & 0.02 & 1.23 biofuel \\
\hline 75 & 7.97 & 4 & 0.01 & 1.10 bioma \\
\hline 10 & 4.98 & 3 & 0.01 & 1.07 coal \\
\hline 24 & 8.52 & 5 & 0.01 & 1.06 biodiesel \\
\hline 13 & 5.25 & 4 & 0.01 & 1.04 bioenergy \\
\hline 17 & 5.80 & 4 & 0.01 & 1.03 ethanol \\
\hline 22 & 8.82 & 2 & 0.00 & 1.02 growth \\
\hline 12 & 4.06 & 2 & 0.00 & 1.01 investment \\
\hline 10 & & 1 & 0.00 & 1.00 environment \\
\hline 26 & & 4 & 0.00 & 1.00 income \\
\hline 30 & & 9 & 0.00 & 1.00 sector \\
\hline 10 & & 4 & 0.01 & 1.00 oil \\
\hline 52 & & 5 & 0.03 & 1.00 energy policy \\
\hline 61 & & 7 & 0.02 & 1.00 emission \\
\hline 90 & & 8 & 0.03 & 1.00 china \\
\hline 23 & & 3 & 0.00 & 1.00 co2 emission \\
\hline 58 & & 14 & 0.02 & 1.00 demand \\
\hline 96 & & 9 & 0.02 & 1.00 energy consumption \\
\hline 138 & & 9 & 0.01 & 1.00 impact \\
\hline
\end{tabular}

Fig. 18. Top 20 Keywords of cited references in Cluster\#2, ranked by Sigma 
EP widely exists in China and other developing or underdeveloped countries, especially in rural areas, where poor people have only access to conventional wood or other biomass fuels for household warm comfort and cooking. Sustainable biomass fuel and mature processing technology will offer an optimal choice to solve EP issues. Although many studies have explored some approaches to develop sustainable biomass energy, some interesting works are still to be done (Tan et al., 2010).

\section{Cluster \#3 - Photocatalysis}

In Cluster \#3, 26 keywords are collected from cited references. Among all clusters, the silhouette value of this cluster is the highest, which is 0.977 , and the median year of all keywords is the latest, which is 2012 . From Figure 11, we can easily find that Cluster \#3 is slightly independent and mainly focuses on how to use chemical reactions, including photocatalysis, to tackle EP issues. That is because some chemical materials, for example, semiconductor photocatalysis or Cobaloximes, are considered to be attractive ways for solving the worldwide energy shortage and environmental pollution issues. These documents are also important in the field of energy poverty, presenting scientific and technological possibilities offered by materials and providing state-of-the-art research activities. The theme of this cluster is verified based on 5 keywords in Table 6 . Most of the highly cited articles shown in Table 3 belong to this cluster.

Figure 19 displays three development phrases of Cluster \#3. The first period is from 1990, the research starting from metabolism and evolution. Metabolism is the general term for all ordered chemical changes in an organism, including photosynthesis occurring in nature, which is the basic thought of photocatalysis, named artificial photosynthesis. Evolution mainly refers to the change of genetic traits in a population from generation to generation, especially in the environment of EP (Heininger 2020). Then, two keywords, performance and water, attract more and more scholars to study, becoming high-impact keywords. The second developing period of the cluster is between 2008 and 2012, four keywords mechanism, hydrogen, visible light, and carbon dioxide shown in timeline view, which are four important components in major photocatalysis systems. The third-period centres on 2016-2018, composite, graphitic carbon nitride, photocatalysis, and heterojunction are main keywords, which are also interesting and popular research fields till now.

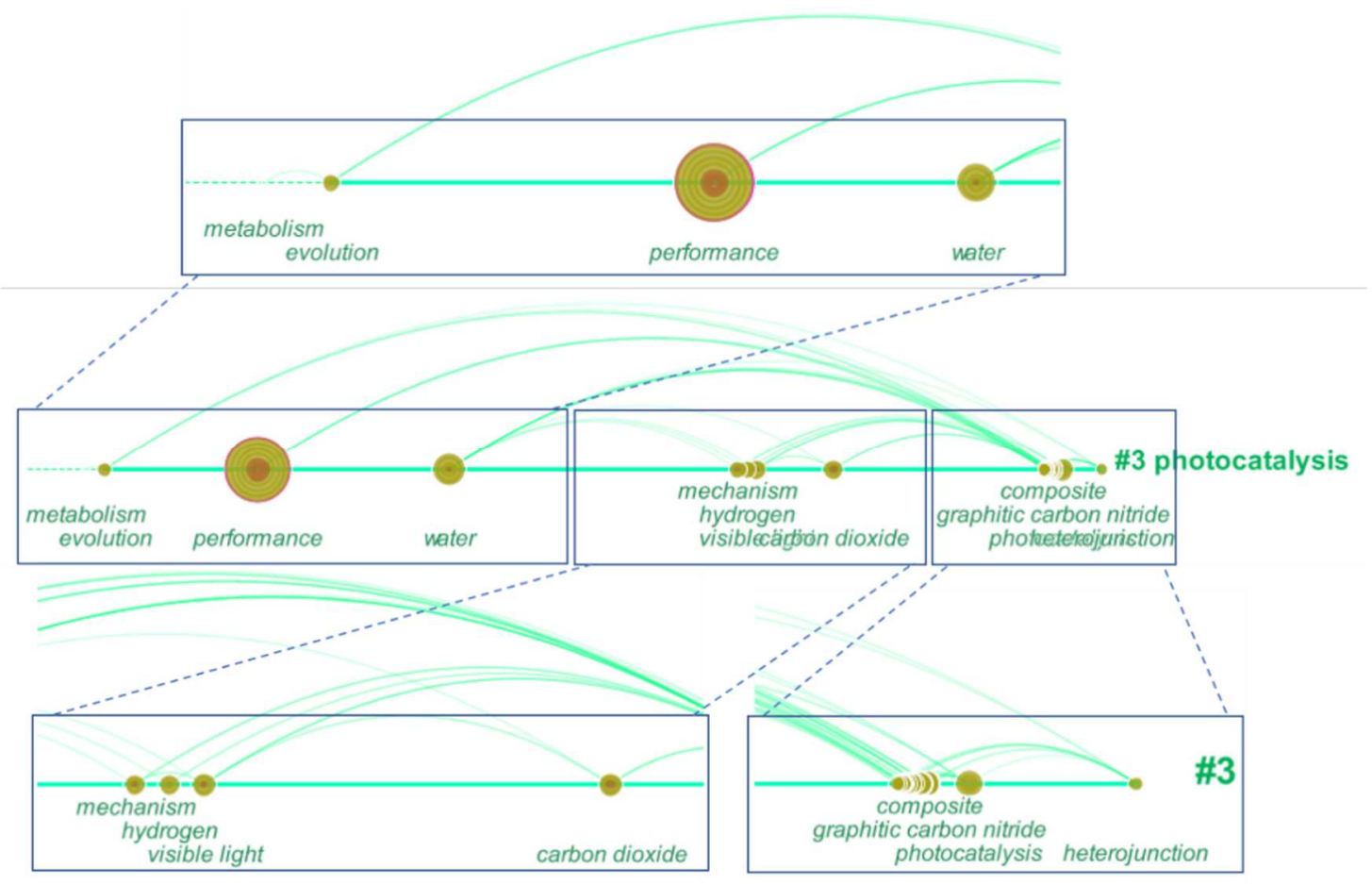

Fig. 19. Keywords in Cluster \#3

Figure 20 displays some keywords collected from cited references in Cluster \#3. Easily we can find that almost all keywords are the same as those in Figure 19, related to chemistry and biology, which implies that the keywords of cited references lay a significant foundation for the research community. Especially, the keyword photocatalysis plays an important role in the cited references as well. 


\begin{tabular}{|r|r|r|r|r|l|}
\hline Freq & Burst & Degree & Centrality & $\Sigma$ & \multicolumn{1}{|c|}{ Keyword } \\
\hline 53 & 4.04 & 15 & 0.01 & 1.06 & photocatalysis \\
\hline 17 & 7.44 & 1 & 0.00 & 1.00 & metabolism \\
\hline 91 & & 15 & 0.08 & 1.00 & water \\
\hline 35 & & 8 & 0.02 & 1.00 & nanoparticle \\
\hline 22 & & 10 & 0.01 & 1.00 & fabrication \\
\hline 30 & & 4 & 0.00 & 1.00 & hydrogen production \\
\hline 36 & & 9 & 0.01 & 1.00 & composite \\
\hline 32 & & 11 & 0.00 & 1.00 & nanosheet \\
\hline 38 & & 7 & 0.04 & 1.00 & evolution \\
\hline 23 & & 3 & 0.00 & 1.00 & reduction \\
\hline 37 & & 7 & 0.00 & 1.00 & visible light \\
\hline 32 & & 12 & 0.02 & 1.00 & degradation \\
\hline 29 & & 5 & 0.00 & 1.00 & catalyst \\
\hline 25 & & 9 & 0.01 & 1.00 & nanocomposite \\
\hline 36 & & 12 & 0.00 & 1.00 & graphitic carbon nitride \\
\hline 36 & & 7 & 0.02 & 1.00 & carbon dioxide \\
\hline 24 & & 1 & 0.00 & 1.00 & carbon \\
\hline 20 & & 10 & 0.00 & 1.00 & heterojunction \\
\hline 24 & & 11 & 0.01 & 1.00 & tion \\
\hline 32 & & 5 & 0.01 & 1.00 & conversion \\
\hline 20.1 & & & & &
\end{tabular}

Fig. 20. T op 20 Keywords of cited references in Cluster\#3, ranked by Sigma

EP is one of the severest issues that people all over the world face. Advanced materials or sustainable energy generated from photocatalytic reactions or other chemical reactions is a promising field for solving the energy shortage. How to design materials with better performance or more efficient chemical reactions to produce sustainable environment-friendly energy has always been a subject worthy of in-depth study. Furthermore, natural life in the environment of EP shows different performances in evolution or reproduction, which should be taken seriously.

\section{Cluster \#4 - Sustainable energy}

The last cluster contains 16 keywords coming from cited references, with a 0.96 silhouette value and 1998 median year of all keywords. Clusters \#1, \#2 and \#3 have mentioned sustainable energy, and this cluster comprehensively discusses several types of novel sustainable energy that is environment-friendly or high-efficient produced, suppling that meets current needs without compromising the ability of future generations to meet their needs, such as renewable energy, solar energy, wind energy, wave energy, clean coal, and nuclear power, as well as technology designed to improve energy efficiency.

We can see four developing phases of Cluster \#4 from Figure 21. In the early year of 1990, scholars mainly paid attention to methane production, digestion and simulation, which are basic research in sustainable energy. After five years, they started to design some effective energy systems and optimise the system parameters for better electrical energy usage, reducing unnecessary consumption and waste. Then, from 2005 to 2007, more and more people devoted themselves to studying some novel sustainable energy like solar energy and wind energy. And at about 2017, they were interested in developing or designing efficient and sustainable capacitors to achieve better energy storage performance.

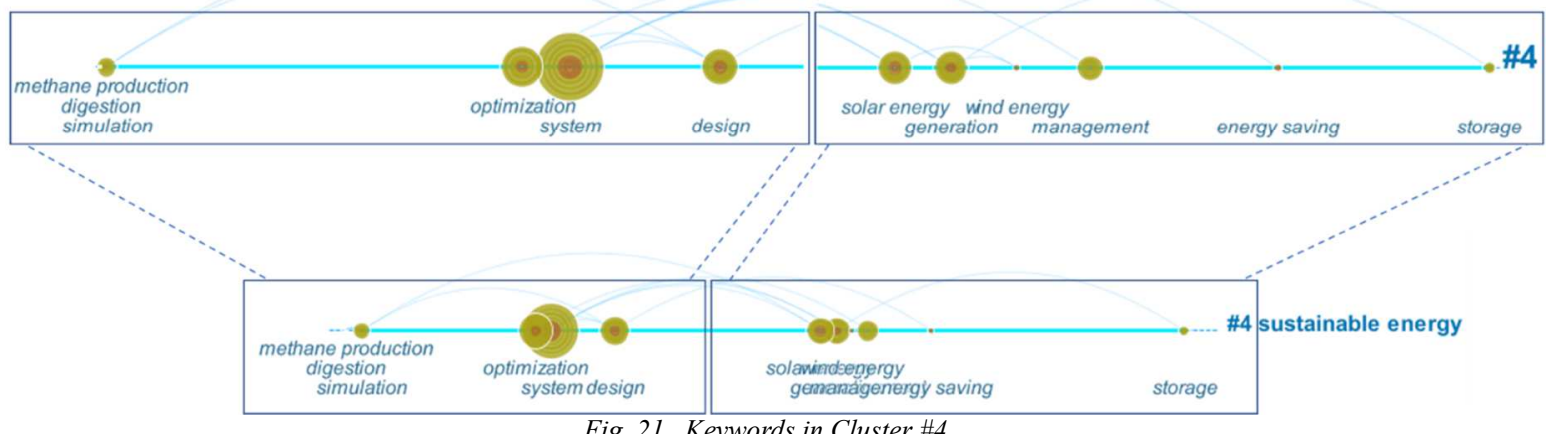

Fig. 21. Keywords in Cluster \#4

The keywords shown in Figure 20 totally emerge in Figure 22, which verifies the keywords in cited references lay a solid foundation for the research community even for further citing articles. They also complement more 
knowledge for understanding the development of specialities. Especially, the keyword solar energy plays an important role in cited references as well.

\begin{tabular}{|r|r|r|r|r|l|}
\hline Freq & Burst & Degree & Centrality & $\Sigma$ & \multicolumn{1}{|c|}{ Keyword } \\
\hline 58 & 6.51 & 5 & 0.04 & 1.29 & solar energy \\
\hline 85 & & 5 & 0.02 & 1.00 & design \\
\hline 1 & & 6 & 0.01 & 1.00 & dynamic model \\
\hline 1 & & 4 & 0.00 & 1.00 & modeling \\
\hline 1 & & 6 & 0.01 & 1.00 & animal waste \\
\hline 65 & & 6 & 0.03 & 1.00 & generation \\
\hline 40 & & 7 & 0.09 & 1.00 & simulation \\
\hline 17 & 7.67 & 1 & 0.00 & 1.00 & energy saving \\
\hline 1 & & 6 & 0.01 & 1.00 & equation \\
\hline 21 & & 1 & 0.00 & 1.00 & storage \\
\hline 14 & 5.01 & 2 & 0.00 & 1.00 & wind energy \\
\hline 1 & & 4 & 0.00 & 1.00 & methane production \\
\hline 176 & & 7 & 0.03 & 1.00 & system \\
\hline 1 & & 6 & 0.01 & 1.00 & digestion \\
\hline 102 & & 4 & 0.01 & 1.00 & optimization \\
\hline 59 & & 1 & 0.00 & 1.00 & management \\
\hline Fig. 22. 16 keywords of cited references in Cluster\#4, ranked by Sigma &
\end{tabular}

As we all know, sustainable energy can be considered as an efficient tool to reduce EP whenever they are conducted based on an appropriate policy. After a long period of development, energy-related pollution emissions, the proportion of clean energy investment, energy intensity and renewable energy utilisation rate have been improved, but per capita, $\mathrm{CO} 2$ emissions, energy dependence and public energy investment still need to be improved.

\section{Conclusions}

As a type of strategic resource, energy is not only related to the national economy and people's livelihood but also connected to national security. EP is a serious whole social issue people worldwide are facing, having a negative impact on economic development, environmental governance, social stability, and people's lives. We collected 3,419 documents from the core dataset of WoS published from 1942 to 2020 and made a comprehensive EP review through bibliometric analysis.

For the fundamental characteristics of documents and journals, the first publication regarding EP existed in 1942, named "Effects of clothing and fuel shortage on health", and published in NATURE. From 1942 to 2004, just a few scholars have paid attention to EP, but the research field has become more and more popular and developed rapidly during recent ten years, with 3,419 publications and 60,516 total citations by 2020 . Thus, the number and citations of documents are both going to be risen up according to the growth trends. Most publications are articles or proceedings papers and are concerned with the energy in society, science, and engineering. The dualmap overlay view of journals exhibits seven main citation tracks found from source journals to target journals and shows similar research direction results. Journals ENERGY POLICY, ENERGY RESEARCH \& SOCIAL SCIENCE, RENEWABLE \& SUSTAINABLE ENERGY REVIEWS, ENERGY AND BUILDINGS published the most documents of EP and the most cited documents (Tong et al., 2012) published in ADVANCED MATERIALS.

From the perspective of country, institution and author, the cooperation profile of EP researchers shows a predominance of international cooperation. China has published the most documents and also had the most cooperation with other countries. Located in the second and the third is USA and UK, respectively. As for the most influential institution, WUHAN UNIV TECHNOL has received the maximum number of citations and followed by are KING ABDULAZIZ UNIV and CHINESE ACAD SCI. It is noted that Top 10 most influential authors focus on three research directions: EP in chemistry or materials, EP in the social, environmental, or economic field, and EP in electricity, engineering, or others. Especially, Top 3 most influential authors are Yu, Jiaguo from China, Cao, Shaowen from China and Sovacool, Benjamin K. from the USA.

According to the keywords of collected documents, different themes of EP are analysed, which is one of the most important tasks in subject bibliometric analysis. Learned from the keyword-burst detection, biogas, energysaving, and smart grid are three recent important keywords of EP literature. Furthermore, five clusters, namely Cluster \#0 - Energy justice, Cluster \#1 - Rural electrification, Cluster \#2 - China, Cluster \#3 - Photocatalysis, Cluster \#4 - Sustainable energy, are derived from keyword co-occurrence network. Then every cluster is analysed in two aspects: the timeline view of keywords and major keywords of cited references. We also demonstrate some literature analysis and insights that researchers are concerned about.

Based on previous results, three recommendations are offered to build a better environment for cooperation and to improve EP researches: (1) public policy should encourage the collaboration of researchers or institutions 
all over the world; (2) promote the interdisciplinarity of various research directions such as EP in chemistry and EP in engineering, which can generate new research topics and further increase cooperation between scholars and institutions, as well as extend the applications when addressing EP issue; (3) establish steady cooperation mechanism and plan some partnership programs between research groups and companies in various countries, especially China, USA and UK.

It is important to note that some limitations of the present analysis should be addressed in further research. For example, all documents just collected from WoS may lead to a bias in the searching process. The bibliometric analyses and additional conclusions largely depended on the results shown in visualised knowledge mapping domains, e.g., VOS viewer and CiteSpace, which cannot escape from the inherent flaws of these tools. Therefore, more reliable documents could be selected from another prestigious Web bibliometric database, Scopus or IEEE, and explore other criteria to evaluate the predominance of publications or determinants of tackling the EP issue in the future.

\section{References}

Aryadoust, V., Tan, H.A.H., \& Ng, L.Y. (2019). A scientometric review of rasch measurement: The rise and progress of a specialty. Frontiers in Psychology, 10, 2197.

Bhide, A., \& Rodriguez Monroy, C. (2011). Energy poverty: A special focus on energy poverty in India and renewable energy technologies. Renewable \& Sustainable Energy Reviews, 15(2), 1057-1066.

Boardman, B. (2010). Fixing fuel poverty. Challenges and Solutions, Earthscan, London.

Borhanazad, H., Mekhilef, S., Saidur, R., \& Boroumandjazi, G. (2013). Potential application of renewable energy for rural electrification in Malaysia. Renewable Energy, 59, 210-219.

Castano-Rosa, R., Solis-Guzman, J., Rubio-Bellido, C., \& Marrero, M. (2019). Towards a multiple-indicator approach to energy poverty in the European Union: A review. Energy and Buildings, 193, 36-48.

Chen, C.M. (2017). Science mapping: A systematic review of the literature. Journal of Data and Information Science, 2, 1-40.

Chen, C.M. (2018). Eugene Garfield's scholarly impact: a scientometric review. Scientometrics, 114(2), 489-516.

Chen, C.M., \& Leydesdorff, L. (2014). Patterns of connections and movements in dual-map overlays. Journal of the Association for Information Science and Technology, 65(2), 334-351.

Chen, Y.H., Chen, C.Y., \& Lee, S.C. (2010). Technology forecasting of new clean energy: The example of hydrogen energy and fuel cell. African Journal of Business Management, 4(7), 1372-1380.

Cortés-Sánchez, J.D. (2019). Innovation in Latin America through the lens of bibliometrics: crammed and fading away. Scientometrics, 121(2), 869-895.

De Paulo, A.F., \& Porto, G.S. (2017). Solar energy technologies and open innovation: A study based on bibliometric and social network analysis. Energy Policy, 108, 228-238.

Dubois, U., \& Meier, H. (2016). Energy affordability and energy inequality in Europe: Implications for policymaking. Energy Research \& Social Science, 18, 21-35.

Falagas, M.E., Pitsouni, E.I., Malietzis, G.A., \& Pappas, G. (2008). Comparison of PubMed, Scopus, Web of Science, and Google Scholar: Strengths and weaknesses. Faseb Journal, 22(2), 338-342.

Gebreslassie, M.G. (2020). COVID-19 and energy access: An opportunity or a challenge for the African continent?. Energy Research \& Social Science, 68, 101677.

González-Eguino, M. (2015). Energy poverty: an overview. Renewable \& Sustainable Energy Reviews, 47, 377 385.

Hamburger, D., Jaeger, J., Bayer, P., Kennedy, R., Yang, J., \& Urpelainen, J. (2019). Shades of darkness or light? A systematic review of geographic bias in impact evaluations of electricity access. Energy Research \& Social Science, 58, 101236.

Han, X., \& Wei, C. (2021). Household energy consumption: state of the art, research gaps, and future prospects. Environment Development and Sustainability. http://dx.doi.org/10.1007/s10668-020-01179-x

Heininger, K. (2020). Aging is a deprivation syndrome driven by a germ-soma conflict. Ageing Research Reviews, 1(3), 481-536.

Herington, M.J., \& Malakar, Y. (2016). Who is energy poor? Revisiting energy (in)security in the case of Nepal. Energy Research \& Social Science, 21, 49-53.

Hill, L. (1942). Effects of clothing and fuel shortage on health. Nature, 150(3810), 536-538.

Howden-Chapman, P., Viggers, H., Chapman, R., O'Sullivan, K., Barnard, L.T., \& Lloyd, B. (2012). Tackling cold housing and fuel poverty in New Zealand: a review of policies, research, and health impacts. Energy Policy, 49, 134-142.

Isherwood, R.M., \& Hancock, B.C. (1979). Household expenditure on fuel: distributional aspects. Economic Adviser's OfficeDHSS, London.

Jain, I.P. (2009). Hydrogen the fuel for 21st century. International Journal of Hydrogen Energy, 34(17), 73687378. 
Jones, J. (2001). UK seeks to prevent 50000 winter deaths from "fuel poverty". British Medical Journal, 322(7285), $510-510$.

Kaygusuz, K. (2011). Energy services and energy poverty for sustainable rural development. Renewable \& Sustainable Energy Reviews, 15(2), 936-947.

Kuang, Y.H., Zhang, Y.J., Zhou, B., Li, C.B., Cao, Y.J., Li, L.J., \& Zeng, L. (2016). A review of renewable energy utilization in islands. Renewable \& Sustainable Energy Reviews, 59, 504-513.

Leister, D., Wang, X., Haberer, G., Mayer, K.F.X., \& Kleine, T. (2011). Intracompartmental and intercompartmental transcriptional networks coordinate the expression of genes for organellar functions. Plant Physiology, 157(1), 386-404.

Li, K., Pan, S.Y., \& Wei, Y.M. (2015). A bibliometric analysis of energy poverty research: results from SCI-E/SSCI databases. International Journal of Global Energy Issues, 38(4-6), 357-372.

Liddell, C. (2012). Fuel poverty comes of age: commemorating 21 years of research and policy. Energy Policy, 49, 2-5.

Lowans, C., Rio, D., Sovacool, B.K., Rooney, D., \& Foley, A.M. (2021). What is the state of the art in energy and transport poverty metrics? A critical and comprehensive review. Energy Economics, 3, 105360.

Martiskainen, M., \& Sovacool, B.K. (2020). Temporality, consumption, and conflict: exploring user-based injustices in European low-carbon transitions. Technology Analysis \& Strategic Management. http://dx.doi.org/10.1080/09537325.2020.1841895

Nora, B., Guo, R., Wu, W.H., \& Liu L.J. (2019). A comparative study of the interlinkages between EP and low carbon development in China and Germany by developing an EP index. Energy and Buildings, 183, 817831.

Palanichamy, C., Babu, N.S., Chelvan, R.K., \& Nadarajan, C. (1999). Restructuring the Indian power sector with energy conservation as the motive for economic and environmental benefits. IEEE Transactions on Energy Conversion, 14(4), 1589-1596.

Schrodervanderelst, J.P., \& Vanderheide, D. (1992). Effects of streptozocin-induced diabetes and food restriction on quantities and source of T4 and T3 in rat tissues. Diabetes, 41(2), 147-152.

Sesan, T. (2012). Navigating the limitations of energy poverty: Lessons from the promotion of improved cooking technologies in Kenya. Energy Policy, 47, 202-210.

Siksnelyte- Butkiene, I., Streimikiene, D., Lekavicius, V., \& Balezentis, T. (2021). Energy poverty indicators: a systematic literature review and comprehensive analysis of integrity. Sustainable Cities and Society, 67(1), 102756.

Singal, S.K., Varun, \& Singh, R.P. (2007). Rural electrification of a remote island by renewable energy sources. Renewable Energy, 32(15), 2491-2501.

Sovacool, B.K., \& Brown, M.A. (2010). Competing dimensions of energy security: an international perspective. Annual Review of Environment \& Resources, 35(1), 77-108.

Streimikiene, D., Lekaviius, V., Balezentis, T., Kyriakopoulos, G.L., \& Abrhám, J. (2020). Climate change mitigation policies targeting households and addressing energy poverty in European Union. Energies, 13(13), 3389.

Su, M.S., Deng, J., \& Zhao, C.R. (2008). Interaction of renewable energy policy and CO2 emission control policy: case study. Journal of Energy Engineering, 134(2), 63-70.

Tan, T., Shang, F., \& Zhang, X. (2010). Current development of biorefinery in China. Biotechnology Advances, 28(5), 543-555.

Tang, X., \& Liao, H. (2014). EP and solid fuels use in rural China: analysis based on national population census. Energy for Sustainable Development, 24, 122-129.

Tarragona, J., de Gracia, A., \& Cabeza, L.F. (2020). Bibliometric analysis of smart control applications in thermal energy storage systems. A model predictive control approach. Journal of Energy Storage, 32, 101704.

Tong, H., Ouyang, S., Bi, Y., Umezawa, N., Oshikiri, M., \& Ye, J. (2012). Nano-photocatalytic materials: possibilities and challenges. Advanced Materials, 24(2), 229-251.

Tsai, W.H., Lin, S.J., Liu, J.Y., Lin, W.R., \& Lee, K.C. (2011). Incorporating life cycle assessments into building project decision-making: an energy consumption and CO2 emission perspective. Energy, 36(5), 3022-3029.

Ürge-Vorsatz, D., \& Tirado Herrero, S. (2012). Building synergies between climate change mitigation and energy poverty alleviation. Energy Policy, 49, 83-90.

Urquiza, A., Amigo, C., Billi, M., Calvo, R., Labraña, J., Oyarzún, T., \& Valencia, F. (2019). Quality as a hidden dimension of EP in middle-development countries. Literature review and case study from Chile. Energy and Buildings, 204, 109463.

Von Stechow, C., McCollum, D., Riahi, K., Minx, J.C., Kriegler, E., Vuuren, D.P.V., Jewell, J., Robledo-Abad, C., Hertwich, E., Tavoni, M., Mirasgedis, S., Lah, O., Roy, J., Mulugetta, Y., Dubash, N.K., Bollen, J., UrgeVorsatz, D., \& Edenhofer., O. (2015). Integrating global climate change mitigation goals with other sustainability objectives: a synthesis. Annual Review of Environment \& Resources, 40(1), 363-394. 
Wang, X.X., Chang, Y.R., Xu, Z.S., Wang, Z.D., \& Kadirkamanathan, V. (2020). 50th anniversary of International Journal of Systems Science: a comprehensive bibliometric analysis. International Journal of Systems Science. http://dx.doi.org/10.1080/00207721.2020.1862937

Xing, Y., Ma, Z., Su, W., Wang, Q., \& Zhang, H. (2020). Analysis of research status of CO2 conversion technology based on bibliometrics. Catalysts, 10(4), 370.

Yadava, R.M., \& Sinha, B. (2019). Developing energy access index for measuring energy poverty in forest fringe villages of Madhya Pradesh, India. Sustainable Energy Technologies and Assessments, 31, 167-178.

Yu, D.J., Xu, Z.S., Pedrycz, W., \& Wang, W.R. (2017). Information sciences 1968-2016: a retrospective analysis with text mining and bibliometric. Information Sciences, 418, 619-634.

Wang X.X., Xu, Z.S., Qin, Y., \& Skare, M. (2021). Foreign direct investment and economic growth: A bibliometric study of measurement approaches and results. Economic Research-Ekonomska Istraživanja. http://dx.doi.org/10.1080/1331677X.2021.1952090 